\title{
ArkaeVision VR Game: User Experience Research between Real and Virtual Paestum
}

\author{
Alfonsina Pagano ${ }^{1, *(0)}$, Augusto Palombini ${ }^{1}\left(\mathbb{D}\right.$, Guido Bozzelli $^{2}$, Maurizio De Nino ${ }^{2}$ (), \\ Ivana Cerato ${ }^{2}$ and Stefano Ricciardi ${ }^{3}$ \\ 1 CNR ISPC, Via Salaria km 29,300-CP.10, 00015 Rome, Italy; augusto.palombini@cnr.it \\ 2 Digitalcomoedia, Piazza Capuana, 15, Via dei Mille, 16, 80139 Naples, Italy; \\ g.bozzelli@digitalcomoedia.com (G.B.); m.denino@digitalcomoedia.com (M.D.N.); \\ ivana.cerato@gmail.com (I.C.) \\ 3 University of Molise (Dip. Biosciences and Territories), Via Francesco De Sanctis, 1, 86100 Campobasso, Italy; \\ stefanoricciardi2@gmail.com \\ * Correspondence: alfonsina.pagano@ispc.cnr.it
}

Received: 13 March 2020; Accepted: 29 April 2020; Published: 2 May 2020

\begin{abstract}
The design of a virtual reality (VR) cultural application is aimed at supporting the steps of the learning process-like concrete experimentation, reflection and abstraction-which are generally difficult to induce when looking at ruins and artifacts that bring back to the past. With the use of virtual technologies (e.g., holographic surfaces, head-mounted displays, motion-cation sensors) those steps are surely supported thanks to the immersiveness and natural interaction granted by such devices. VR can indeed help to symbolically recreate the context of life of cultural objects, presenting them in their original place of belonging, while they were used for example, increasing awareness and understanding of history. The ArkaeVision VR application takes advantages of storytelling and user experience design to tell the story of artifacts and sites of an important cultural heritage site of Italy, Paestum, creating a dramaturgy around them and relying upon historical and artistic content revised by experts. Visitors will virtually travel into the temple dedicated to Hera II of Paestum, in the first half of the fifth century BC, wearing an immersive viewer-HTC Vive; here, they will interact with the priestess Ariadne, a digital actor, who will guide them on a virtual tour presenting the beliefs, the values and habits of an ancient population of the Magna Graecia city. In the immersive VR application, the memory is indeed influenced by the visitors' ability to proceed with the exploratory activity. Two evaluation sessions were planned and conducted to understand the effectiveness of the immersive experience, usability of the virtual device and the learnability of the digital storytelling. Results revealed that certainly the realism of the virtual reconstructions, the atmosphere and the "sense of the past" that pervades the whole VR cultural experience, characterize the positive feedback of visitors, their emotional engagement and their interest to proceed with the exploration.
\end{abstract}

Keywords: VR game; 3D reconstruction; storytelling; 3D models aesthetics accuracy; user experience design; user evaluation

\section{Introduction. User Experience Research in cultural heritage}

Working on cultural heritage $(\mathrm{CH})$ through virtual technologies allows us to establish a more intimate and profound "dialog" with visitors, given the potentialities of such devices to virtually recreate ancient scenarios of life, where artifacts, landscapes, environments and characters (re)live together in a coherent combination. Visitors, always more, look for interactivity and immersiveness during their cultural experience [1-3]; they want to get in contact with the past, with all their senses, by direct experiencing places and objects through everyday gestures and behaviors (natural interaction) 
as well as by feeling that they are embodied in the augmented reality mainly through the sight (sense of immersion). Multi-projection systems, holographic applications, immersive viewers, Augmented reality (AR) systems support the virtual immersion into reconstructed scenarios of the past at different levels [4]:

- $\quad$ See-through and monitor-based AR displays provide users the illusion of admiring no more visible elements of the past, for example columns or colors, directly on the archaeological remains through the juxtaposition of the virtual model on the visible item by means of a device (tablet or a semi-transparent display). In case of holograms, the virtual contents are displayed thanks to an illusory technique better known as Pepper's Ghost which uses a game of reflections to project virtual elements (images or videos) from a display on a transparent glass, Plexiglas or other plastic film to give the illusion that these elements appear inside environments and interact with objects or physical persons. In addition, the HoloLens technology is based on this approach: this wearable device indeed offers stereoscopic fruition while maintaining an overview on the real word. In case of AR displays using tablets, the system works applying superimposition or juxtaposition of virtual images and real ones framed by the camera of the device [5].

- Multi-projections allow the superimposition of virtual elements (lights, images or videos) directly on real surfaces and physical structures, through projections mapping techniques and letting them coincide. Users are here at the center of a visual show which, in some cases, gives them the impression of being surrounded by ancient elements like architectures of a Greek temple or a Basilica at 1:1 scale, as they would have appeared in origin; alternatively, users can participate to a digital storytelling taking place around them on a very big surfaces, generally supported by open-air soundscape.

- Head-mounted displays (HMD) are the most powerful in terms of immersion into virtual worlds, thanks to a total visual occlusion of users while wearing such devices, as well as a complete sound isolation due to the incorporated earphones; virtual scenes happen in front of users' eyes, but at a greater level of embodiment: they can see their bodies transposed into the 3D scene and they can directly interact with the digital elements as in real life-by touching, manipulating and moving them using hand devices, as well as walking.

Every technology has thus its own level of immersion into digitally replicated cultural environments, according to the used device-tablet, wearable tool or projections. Each one involves users on a different perceptive levels: AR and holograms have an impact on the sight on a limited field of view, ensuring the spatial contiguity's principle; HMDs involve the sight a $360^{\circ}$ and sometimes also hearing and body gestures (hands' movement and walking), providing a full body experience; multi-projections work on "contextual" stimuli which users can grab with the sight and the hearing-also absorbing surrounding noises (crowd, noises of the city's activities ... ) and physical obstacles (dimensions of the wall projection, any occlusion point, architectural inaccessibility ... ).

The cognitive process-attention, motor \& action, visual-spatial perception, language and memory-is therefore relevant to understand how people experience $\mathrm{CH}$ through digital technologies-like the ones above mentioned. Perception is surely of our interest; it refers to a process of sensory stimulation and significance that our mind activates once in front of something. Visual perception and proprioception represent the prime cognitive faculties, since with our eyes and body that we know the world around us. In addition, in virtual reality (VR) this is still a prime way to explore and live the three-dimensional spaces. Sensations and perceptions are thus involved in the experience and in the learning processes, as it is presented in David Kolb's experiential learning model (ELM) [6] and in Bloom's taxonomy of cognition and social context [7-9].

Cognition and emotions are strictly related and depending one to another: the former is the mental process of knowledge acquisition and understanding by senses, thoughts and live experiences [10,11]; it generates attention, memorization and comprehension, generally processes that use existing knowledge to generate new knowledge. That is also what usually happens when we interact with a 
VR environment: the use of a device to access cultural information recalls the memory of something already familiar to the user (like quotidian gestures and movements). Social transmission and the cultural growth, therefore, take into account the reusability of our past experiences, the lessons learned and the emotions felt. In contrast, emotions work as indicators of the "quality" of such experiences and, together with reasoning, push us in a direction or another, making this or that choice.

Virtual technologies that enter museums and cultural places, can therefore increase both the concrete meanings of heritage, as well as the personal meanings emerged by the direct experience of users $[12,13]$. Exploiting thus the potential offered by the virtual can surely improve the communication of cultural heritage making the cultural offer more attractive to different user groups. Not only. The focus is improving the User eXperience (UX) of the cultural object or site they are living, so to transform that moment into an "augmented", and even customizable story-a new piece of memory $[4,14]$.

Indicators such as the usability of the virtual applications, the visibility of the elements that set up the graphic interfaces, the different user's perception related to the ergonomics and handling of digital devices, as well as the level of emotional involvement with the story of such applications, the satisfaction generated by the use and the vision of virtual objects and environments, the levels of comprehensibility and memorization of the cultural contents, are just some of the records that are crucial for the design of new user experiences and for the success of any cultural communication project [15]. All these features have a deep impact on the (cultural) knowledge acquisition and retention; the latter can vary, on one hand, according to the absorptive mental faculty of individuals, their disseminative capacity and social perspectives; on the other hand, they can depend on the communicative models, channels and mechanisms employed as well as the languages and the storytelling techniques [16-19].

Several studies on museum visitors using virtual technologies, allowed indeed researchers to identify which aspects of the UX influence knowledge acquisition and retention and under which conditions $[4,5,20,21]$. What came out is that the users' visit path inside cultural venues, the time spent using digital applications, the users' behavior towards the museum items (active or passive visitors, in a group or alone) largely affect the content understanding and memorization. The same cultural information delivered through VR depends on the structure, the language and the style chosen by authors-even if it is not always easy to relate the content style to the chosen technology The above mentioned studies revealed also that a prevalent part of the visitors is usually very intrigued by virtual technologies, at the very beginning, and they want to try them quite immediately. However, once the surprise and discovery effects are ended, visitors' attention tends to decline very quickly if any attractive, meaningful content is not presented. In order to maintain a high level of attention and motivation, working on content is thus essential: experimentation on narratives, representation and dramatization forms and new storytelling techniques are advisable in the cultural heritage field and they affect the choice of technology that can be done from time to time.

On a wider perspective, users' digital fruition needs to be considered at 360 degrees when designing UX inside museums or archaeological sites. This is the challenge of this contribution: how to introduce elements of virtual spectacularization during the experience of a museum and the archaeological site? How to support the activation of curiosity, attention and interest in visitors to let the learning process to take place? How do we develop new forms of narration at the museum through emotions? How do we create a digital product capable of expanding the museum supply, enhancing its visibility and promoting interactive dynamics?

We present an immersive VR application, ArkaeVision Archeo, which stands as an experiential journey through time and space from the modern city of Paestum, located in the south of Italy, to its ancient Poseidonia back to the fifth century BC. We try to address the above-mentioned research questions considering the relevance of the design of UX in cultural contexts.

In the following sections we discuss how cultural experience can be addressed, shaped and evaluated in order to understand if VR technology can "substitute" the human cognition to let individuals feel, see and finally relive the past. We tackle the notions of emotion, memorization and 
learning referring to $\mathrm{CH}$ experience, explaining how these are connected and how emotions affect the way users feel and see the reality and the virtual world, and, consequently, the way they learn and foster the cultural information; (Section 1.1); we then focus the attention on how digital technologies influence such notions (Section 1.2) especially Immersive VR (Section 1.2) and its capability to make users feel embodied with the virtual world, emotionally and cognitively. The social and historical background of Paestum-Poseidonia will be shortly introduced in order to make clear the context we wanted to provide for the VR experience (Section 2.1); values, behaviors and social activities will be chosen ready to be transposed in the VR application (Section 2.2). The ArkaeVision experience and its design will be then presented (Section 3) as well as the centrality of users and their choices in such VR experience. In order to support and validate the work done by designers and computer scientists, as well as archaeologists and UX researchers, two evaluations during public events will reveal if ArkaeVision worked in terms of learnability and sense of involvement in the ancient Poseidonia, but also usability and general appreciation (Sections 4 and 5). It will close the contribution a discussion section on the importance of the role of users' emotions in approaching $\mathrm{CH}$, the role of VR technology into museums and cultural venues and how the UX design can support and enhance future research projects (Sections 5 and 6).

\subsection{See, Feel, Remember the Past: Which Connection?}

Users' interaction with places, objects and other people generates stories, those that cultural objects are witnesses of in museums or archaeological sites. Nevertheless, most of the time these stories do not emerge in exhibit contexts; they are not made evident because artifacts and sites are reduced to simple labels or panels explaining very poor information like materials, age, provenance and dimensions. Such data are often for experts' readability and do not reveal or explicit units of information useful for the general audience to understand how that object or site were in origin. Moreover, the fragmentation and the essentiality of most of museum objects or archaeological traces, make difficult to see the original shapes and the colors, for example, or the grandiosity of the architectures, their volumes and disposition. All these aspects do not emerge very often when visiting cultural venues. Hence, users' readability of the past is influenced by the visibility-ascribable to the state of conservation of objects and sites.

Nevertheless, with the aid of virtual technologies, imagining the past can be supported. Technology makes "visible" images, concepts and meanings immediately on a device or directly on the real objects or sites $[22,23]$. The aesthetic features of a vase, for example, the provenance, the materials used to melt it and the ergonomics, tell a lot of that artifact and help users to mentally assign it to a time period, to a specific function or recognize its preciousness. But not exclusively. Information like the owners of that vase, what it contained, the conditions of its discovery, the context of use, and anecdotes coming from its "daily life" support the reestablishment of the object's story and its social and cultural environment. This story is what intrigue visitors [24,25]; it involves them from an emotional point of view and allow them to almost feel the moment when the vase was used. Moreover, being so involved in the story-telling, support visitors to keep memory of what just heard once they come back home [22].

Relations between emotions and memorization find evidence in multiple researches. A study of the cognitive psychologist Donald MacKay, who conducted an "emotional Stroop test" (2004) [26], highlighted the connection between emotive state of users and their information retention. Different words were presented to users and each word had different color; users were then called to name the color as well as the words after a while. MacKay discovered that prohibited words, which were provided to obtain an emotional effect, were recalled more than others. The results of the experiment-and other ones conducted by his team-suggest that the emotional status in which we are when we do/listen to/watch at a subject can positively influence the registration of information into the short (or even long-term) memory.

Two academics in the fields of neuroscience and behavioral science, Arne Öhman and Susan Mineka, after several studies affirmed that while emotions emerge beyond our conscious control, 
their instinctiveness warn us of any threat or danger it may occur in our surrounding environment. For example, the feeling of happiness produced by a secure context, like our home, may influence us to choose lower risking behaviors-due also to lower defense barriers.

Other studies suggest that the brain focuses more easily on emotive stirrings. This was proved by the psychologist Harald Schupp [27-29] and his team, who experimented how different set of images and pictures may stimulate an emotional response in users. Schupp discovered the latter's attention increased when emotional images were presented to them, pointing out that our attention is instinctively pulled to emotive subjects.

In another experiment, the psychologist Stephen D. Smith [30] proved that participants' ability to remember neutral information was limited due to emotive stimuli presented very shortly beforehand. Hence, the phenomenon of the attentional blink - which generally occur when switching the attention from one subject to another-was somehow influenced by an emotional component. Smith and his team drawn down to the conclusion that we may not fully remember a subject if we focus our attention on something emotionally involving immediately before.

Some researchers pushed their studies foreword trying to understand which type of information memory recalls and how these are related to emotions. The social scientist W. Richard Walker [31] studied the memory recall of hundreds of users; he discovered that positive memories were easily remembered of the ones with negative significance. As a result, we can say that positive memories generally provoke emotional responses which are stronger than the ones provoked by negative memories [32].

While a positive approach to the users' interaction with the surrounding environment (real and virtual) activate the emotional component, which is a powerful "tool" for storing and recalling information; it is also important that the acquired information is actively connected to the knowledge already present in our memory. How is this possible? For example, by making connections with one's own experience, exchanging impressions and opinions with other visitors, finding oneself deeply projected, reflected and motivated within the physical and virtual world that is being traveled through, etc. $[33,34]$. Knowledge acquisition and retention are therefore not linear processes but moved by our emotions and the quality of our experiences.

The American pedagogist Edgar Dale (1900, Minnesota; 1985, Ohio) found early in 1969 that our memory is more influenced by our multisensory experiences [35-37]. The more these experiences are special, full of emotions, the more we will remember them easily even after some time. From Dale's studies the famous "learning cone" or "cone of experience" was born (Figure 1), which saw many re-modulations and adaptions according to the field of appliance in which it was took as reference.

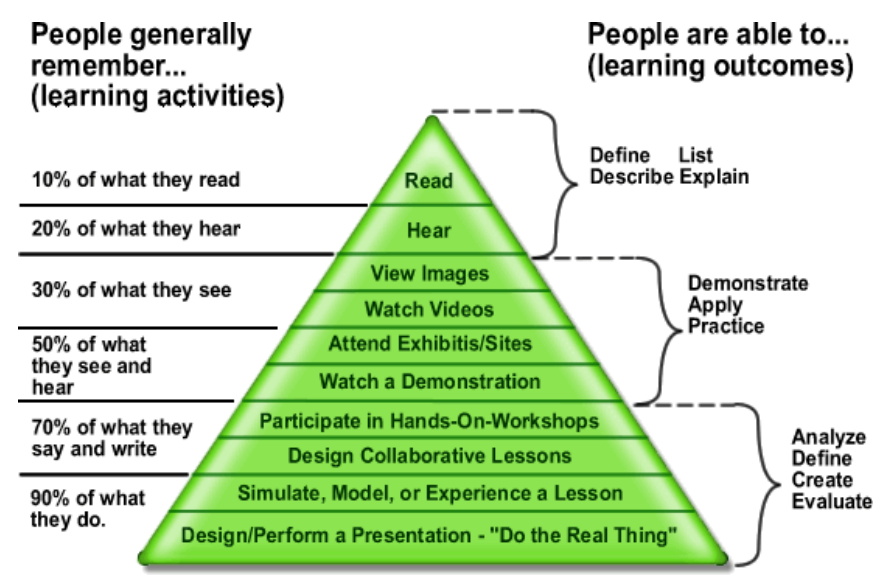

Figure 1. cone of experience (Source: This file is licensed under the Creative Commons Attribution-Share Alike 3.0.) deducted by E. Dale. 
Dale's cone of experience tries to put in a progressive sequence the learning experiences and "the gradual loss of sensory information" as individuals moves from the bottom to the top [38]. In its original formulation, the cone was not meant to depict a value judgment of experiences, as Dale stated; it was mainly designed as a visual support to try to position the various types of audio-visual materials in the learning process.

Despite being a guide, rather than an effective model, the cone suggests which stimuli and channels were functional to soliciting attention, memorization and understanding in individuals; the concept was to practically involve all senses in the learning process and return the individual an active proponent of content. Dale explained indeed that our sensory organs needed to be awakening for retention and understanding to take place, taking advantages of multiple learning models. The latter were classified into two broad categories:

$\begin{array}{ll}\text { - } & \text { passive learning } \\ \text { - } & \text { active learning }\end{array}$

Passive learning (reading and listening) may lead to lower memorization percentages while active learning (say and do) to the highest ones. Active learning is often based on concrete and contextual experience (so-called Experiential learning or learn-by-doing) [39]. This process takes place through the enactment of actions, behaviors and tasks in which users find themselves fielding their abilities and mental faculties for the elaboration and/or reorganization of new pieces of notion. Experiential learning allows users to handle new situations by developing adaptive behaviors and, at the same time, improving the ability to manage emotions $[6,40,41]$. Nevertheless, we understand not only through doing; the active role of users is not enough and must be accompanied by reflections and emotions, otherwise only mechanical actions would be memorized [42]. It is necessary to reflect, think, acquire awareness of the actions and feel their relevance for our life.

Both categories of learning take advantage of the sight which is the most developed sense [43-46]; it is a typical feature of the human being (and few other animals) which uses visual stimuli to explore, analyze and understand the surrounding space. About $80 \%$ of information that the human brain receives comes from the eyes. Not exclusively images, but also sensations and emotions have a relationship with the vision and the hearing. Indeed, the importance of sound information, combined with visual information, also emerges from Dale's cone. Sound is capable of arousing an emotional reaction even more immediately than an image; the fusion of the two reaches the maximum of effectiveness [47]. Therefore, it is fundamental that the visual and auditory systems are effective as possible given their centrality for the influence on individuals' behavior [48].

This apply also today to virtual technologies which exploit at the maximum the perceptive channel of the sight. Immersive VR excludes indeed the vision of the external reality from the users' field of view by replacing the virtual one [49]. The progressive separation from real to virtual requires a cognitive effort for users who need to re-contextualize their actions and re-perceive their own bodies. This active process made by users allow them to feel included and "be present" in the virtual environment, abandoning the exact awareness of the real space in which they are set into. Moreover, the chance to use body gestures and physically move into the VR (thanks to hand devices or tracking tools) contribute to stimulate the sense of immersion.

Speaking about HMDs, their visual potential highly depends on the accuracy of virtual content. Such a precision is intended as the "degree to which the virtual environment simulates the real world" [50,51]. It can refer to (a) the physical-sensory accuracy, i.e., visual, acoustic and tactile; (b) the psychological accuracy with which the VR system replicate the psychological mechanisms experienced in reality; (c) the functional accuracy related to the operating principle of the elements in the virtual scene. As much as the visual aspect of VR environments and interactions simulate the ordinary world and behaviors, users feel the continuity from real to virtual, and consequentiality tend to experience the 3D reconstructed scenario. In general, what most influence the immersive VR, from the user's point of view, are: 
- Point of interest. Users can be free to watch anywhere within the virtual scene. It is very important for researchers to study how to structure the simulated space and how to attract the users' attention to certain spots. Recently, experimentations on sound recognition and visual cues are exploiting new modalities to address users' eyes and make them move along a predetermined pathway.

- Orientation in virtual space. It is necessary to provide users information that allow them to orient in VR by defining static and dynamic elements in the scene.

Therefore, the realism of the three-dimensional graphic representation enhances the users' sense of presence within the virtual world because it is connected with the degree of awakening of sensory organs, especially the sight and the hearing. For this reason, the cone of experience of Dale can be still a valid framework to refer to when designing any virtual experience as immersive learning environments.

Dale's cone of experience can be associated with Howard Gardner's theory of multiple intelligences, developed in the 1980s $[52,53]$. According to academics, there are three general categories representing the ways we know and understand the world: visually, auditory and kinesthetically. Beyond these, there are other styles of learning which help awaken the sensory organs of each of us and help achieve self-education. Such styles were codified by Gardner as "intelligences" (linguistic, logical-mathematical, spatial, bodily kinesthetic, musical, interpersonal, intrapersonal, naturalist intelligence). Despite some criticisms in missing a supporting empirical research on the subject, the theory of multiple intelligences suggests eight possible ways to learn. It basically supports the same Dale's concept of exploiting all human senses to experience the reality, but also virtual scenarios, in order to grab and assimilate information, sensing the context in which we are included and finally remembering what just experienced.

\subsection{Digital Technologies and (New) Experiences of $\mathrm{CH}$}

Digital technologies allow to address cultural content to different user groups, providing new communicative strategies according to the devices at disposal. Three-dimensional environments can be enjoyed through a desktop-based tool (PC, tablet, smartphone) whose interaction can take place with a mouse, a joystick, a touch surface or through other peripherals (data gloves, motion sensors, etc.). Content can be organized like an interactive storytelling or a simple movie (following the criteria and the rules of cinema-like products). virtual applications can also be experienced into delimited physical spaces where users can walk into the defined area. Moreover, users' position and orientation can be detected thanks to trackers and sensors. In this case, contents can be distributed in the space and they can appear on multiple levels of synchronicity and with different scales, pushing users to watch them in different directions and distances. Another device is surely the HMD: this solution, equipped with a stereoscopic viewer, offers a three-dimensional perception of the scenarios; it allows the perfect correspondence between the movements of the users' head carried out in the physical space and those in the virtual one, thanks to a tracking system; the interaction with the environment and the virtual objects can be possible using a controller, like joypads, positional controllers or through interactions based on pupillary tracking.

All the above-mentioned technologies differ one to another, according to the following features $[1,3]$ :

1. the structural and ergonomic aspect of the technological solution, therefore relating to its physical accessibility (Can it be used by all users?), its technical components, its size (e.g., tablet vs. holographic showcase) and its location in physical space (e.g., desktop-based system vs. projections);

2. the content of the technological solution, the language used, as well as its level of science and style;

3. the interface design of the technological solution, its visual aspect, the recognizable elements (e.g., icons, written texts, images, visual effects), their position, size and logical coherence in order to be appealing and attractive to the final users; 
4. the possibility of interaction, the models of usage of the technological solution, the logic that underlies the accessibility of contents, their relationship, the possibility of having single or multiple interactions creating participatory experiences also with other users.

These features, according to how they are combined together from time to time, highly influence the UX of any $\mathrm{CH}$ object or site [4]. In order to design effective and meaningful experiences, we need to start from the analysis of the content, the core of our communicative project, rather than the selection of the technology. The latter is a mere technical support used to strengthen certain communication paradigms $[4,5]$.

Specifically referring to immersive VR technology-applied to the ArkaeVision project-users can benefit at the maximum from the visual experience because of the way the content is modulated: a sort of perceptive storytelling can be applied, allowing users to follow a storyline through the sight and the hearing, but also making intentional choices after emotional stimuli are provided by the VR environment. We can say that a synesthesia [5] takes place when using immersive virtual technology: our senses are called to do their part in the process of meaning-making of the cultural experience. VR indeed allows to "travel through space and time without stepping out of the museum building. The potential to transcend the physical location of the built environment [...] has led museums to consider virtual reality as a necessary component in the arsenal of tools to educate, entertain and dazzle" [54]. Users can experience VR according to their level of technological alphabetization; they can decide to be active in the exploration and interaction or passive users; they can stay at home or use VR directly on the cultural site; they can deepen the content according to their interests and curiosities; they can experience VR as much as they want according to the time at their disposal. The possibility to visit ancient locations, approach ruins and statues no longer existing, interact with typical characters, makes visitors feel involved in the exploration, be careful to details (as it is not always possible in physical cultural visits) and be decision-makers of any action and interaction-indirectly enhancing their knowledge [55].

Unfortunately, not all the users can take advantage of VR technology. People with visual disabilities (blind, visually impaired ... ), cognitive limitations (epilepsy, schizophrenia ... ) or, simply, disturbs connected to the body's equilibrium, cannot experience tridimensional immersive products. Another issue can be the motion sickness(dizziness, nausea, disorientation) which is typical of viewers and it related to the well-known conflict between the vestibular system and the visual system; such a discomfort does not prevent users to experience the immersive VR, but, in some cases, they prefer not to try it for precaution or may feel bad afterward. Research on this topic has shown that the sensory conflict mainly depends on the interaction models, how the 3D experience is set, which are the requested movements rather than by technology in itself [56]. As a consequence, a rich variety of locomotion techniques has been developed $[57,58]$ to comfortably explore the virtual environments.

To an end, in the field of digital cultural heritage (DCH), VR technologies should allow to see and feel cultural artifacts and landscapes at 360 degrees. Experiencing the objects of material culture means indeed to involve emotions arisen from all human senses. The sight can help to see and appreciate a statue or a place which have undergone modifications along ages; the touch can help to feel shapes, forms, textures and even the temperature of some artifacts trying to figure out how they could be in the moment of their maximum splendor; the hearing can provide imagination with details about the past, generating emotions.

\section{Experience of the Past and the Present through Gamified Perceptive Storytelling}

The modern reflection on the past represents a key element in VR applications for DCH, both from the points of view of the plot and the characters. These differ in the construction (a) by the complexity of events and interactional dynamics and (b) by the plausibility of facts and subjects $[59,60]$. The setup of all these elements makes the storytelling and the game-based environments favorable for educational activities [61], gradually shifting the quality of VR applications from the purely playful to the educational level. 
The elements of mystery, exploration and recall of ancient worlds have always been crucial factors for planning any immersive narrative environment, like ArkaeVision VR application, as well as for shaping up the protagonists and their adventures through gamified solutions [62,63]. Addressing the digital narrative structure poses some crucial issues connected to the storytelling strategies and to the rules set up by the serious-game domain [64]. First of all, it is a matter of designing a VR application with a high level of immersiveness and with reliable elements of user interaction-not easy to realize in the virtual, given the complexity of human movements and behaviors. Second, the narrative plot-on which the user's personal adventure is set upon-is not linear since it must adapt at the user's choices into the VR experience. Moreover, the aim of an interactive VR experience is generally to provide engagement and learning effects too. Such a goal forces researchers, developers and graphics to harmonize the entertaining and the scientific aspects of the representation of the past. As a matter of fact, the activity of dissemination, done by archaeologists and historians, follows different ways and criteria in comparison with the same activity performed by artists and entertainment operators. Dealing with the reconstruction of costumes, music, environments and every item linked to a particular historical context, imposes indeed two different perspectives: scientists tend to rely on documents and archaeological records, in order to create an environmental setting as close as possible to the historical truth; whereas, artists and storytellers do not pursue the historical "reality", but the chance to make the public closer to their "imaginary" of that Past, as to recreate the "taste" of the epoch they are representing. For instance, our feelings about some movie genres are associated with music styles which have marked the history of cinema (e.g., western or peplum soundtracks) and which provide us a strong sensory immersion; nevertheless, such music was not played at that time. The same goes for the scenographic style of movies: Spielberg's "Schindler's list" was produced in black-and-white as to recall the feeling of video documents from the 40 s, i.e., a powerful incentive for our emotion, but certainly does not resemble the way reality looked like [60]. It is not easy therefore to harmonize these two perspectives. The paradoxical effect of the convergence of multiple professionals and points of view on the virtual reconstructions of the past is that a VR application may become in itself a sort of artwork-a new outreach for VR applied to $\mathrm{CH}$. Acting on the basis of individual capability to evoke the atmospheres of an ancient world and using existing emotional "placeholders" may thus produce a stronger impact, empowered by the user's consciousness of the scientificness of narration $[65,66]$.

In the ArkaeVision VR application, the experience of the Present and the past relates to the city of Paestum, located in the south of Italy, Campania region. Its long lasting tradition [67-70] and the multiplicity of the historical events that characterized the city have been the fertile ground to develop a gamified perceptive storytelling about the Etruscan funerary rituals and celebration habits, the civilization conflicts, the features of classic deities, the priestesses' profile, etc. Paestum, since the Greek colony of Poseidonia (fifth century BC), through the Lucan age, the Roman empire, up to modern time, in the framework of the Bourbon reign as protagonist of the Grand Tour epoch, will be enjoyed by visitors on a deep emotional level. The inspiration to the vedutismo pictorial style of 3D reconstructions, the warm colors of scenes, the natural soundscape and the intimate social interactions are choices made on purpose by authors (Figure 2). Thanks to storytelling and evocative effects, in the ArkaeVision project, objects and places turn into means to create contextual historical dramas on specific themes, built on data previously checked by scientists and experts in $\mathrm{CH}$ and $\mathrm{DCH}$ [5].

In the next paragraph, the historical background of the city of Paestum will highlight the importance of some archaeological structures, still traceable and today accessible, that will be used as natural setup for the VR application. Sacred artifacts, everyday-life objects, costumes and rituals will be described and reused for the virtual storytelling as well as characters and voices will be presented and then transposed in the virtual Poseidonia. 


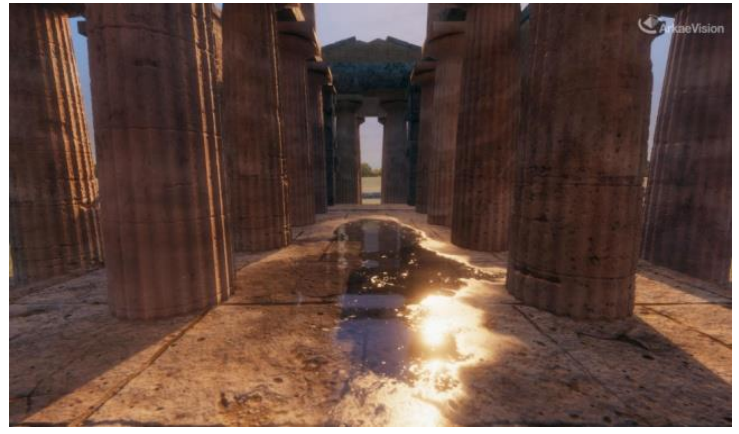

(a)

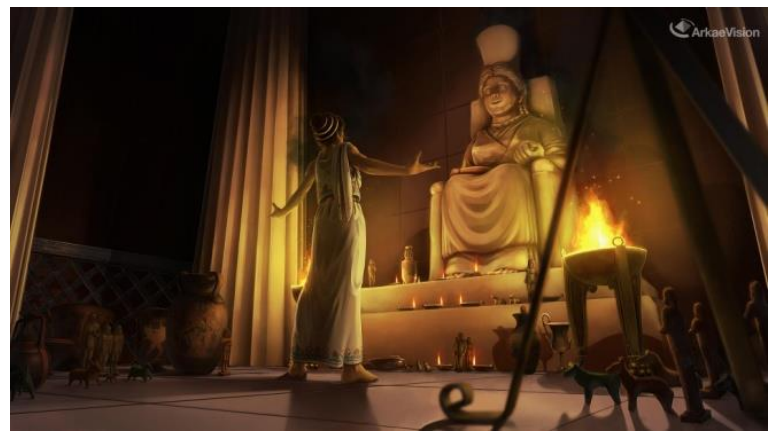

(b)

Figure 2. Screenshots taken from the virtual reality (VR) application of ArkaeVision Archeo: (a) exterior of the naos in the present day and (b) interior of the naos in the fifth century BC with the priestess Ariadne. Copyright (C) Digitalcomoedia.

\subsection{Historical Background: The Temple of Hera II and the Poseidonia's Landscape}

The original name of Paestum was Poseidonia; it was a Greek colony founded on the west coast of Italy, $80 \mathrm{~km}$ south of Naples. It was a very important trade center, first conquered by the Lucanians and then, in the III century BC, the city became an important Roman colony with the Latin name Paestum. Today, it is one of the most important archaeological sites due to its preserved Greek temples [71].

According to Strabo [72], Poseidonia was founded by Greek colonists coming from Sibari; the date of Poseidonia's founding is not given by ancient sources, but the archaeological evidence: approximately the $600 \mathrm{BC}$ [73]. The colonists built fortifications on the coast before moving inland to build their city. Between the VI and V centuries BC, the city was planned out in a precise grid pattern and surrounded by walls. In the central part of the city, in a space of about 10 hectares, a large agora was built- the political heart of the city. Inside it, the most representative public monuments could be found: the heroon, dated around 520-510 BC, dedicated to Poseidon, the mythical founder of the city, the ekklesiasterion, built around 480-470 BC for political assemblies and the temple of Zeus Agoraios (Figure 3).

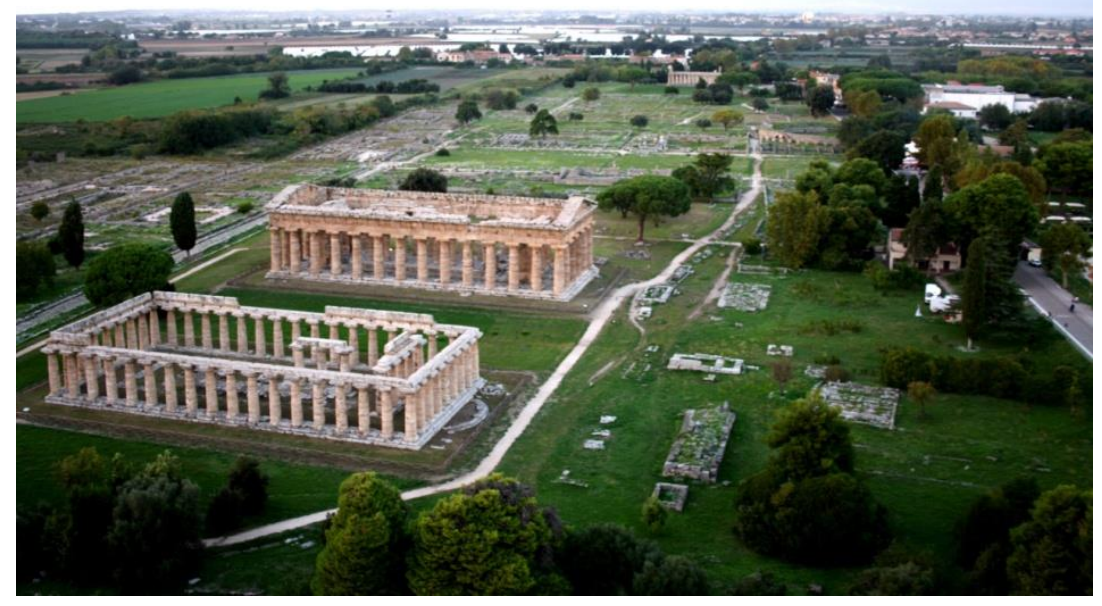

Figure 3. Aerial view of Paestum, looking northwest; two Hera Temples in foreground, Athena Temple in background, the modern museum on right. Copyright (C) V. Alfano (Source: Own work, CC BY-SA 3.0. https://commons.wikimedia.org/w/index.php? curid=21788866).

The colony prospered so that by the VI century BC there was an important sanctuary [74] in the countryside (locality of Foce del Sele) as well as and monumental temples [71]. In the southern sanctuary two Doric temples were erected, the oldest one, the Temple of Hera I of the $550 \mathrm{BC}$, named 
by archaeologists in the 18th century "the Basilica" because someone mistakenly believed it to be a Roman building and the Temple of Hera II, also known as the Temple of Neptune (it also is possible that the temple originally was dedicated to both Hera and Poseidon), built around $460 \mathrm{BC}$ [75]. On the highest point of the town, far away from the Hera Temples going north way, the Temple of Athena can be found. It was built around $500 \mathrm{BC}$, and it was incorrectly associated with Ceres.

In the late fifth century BC, Poseidonia was attacked by the Lucanians, a population of Samnite warriors, coming from the hinterland. The conquerors, who changed the name of the city to Paistom, respected spaces and functions of the places of the Greek city [76].

The monumental and best preserved of temples at Paestum is the so-called Temple of Neptune, built in the Doric order around 460-450 BC, though it was almost certainly dedicated to Hera [77] -the subject of ArkaeVision Archeo reconstructed environment. The frontal view of the temple shows that the entablature is complete. However, no traces of suitable statues have been found anywhere at Paestum and it is clear that the pediment was not carved (Figure 4). However, it may have been painted, and would have given a rather different impression from its gaunt seriousness today (Figure 5).

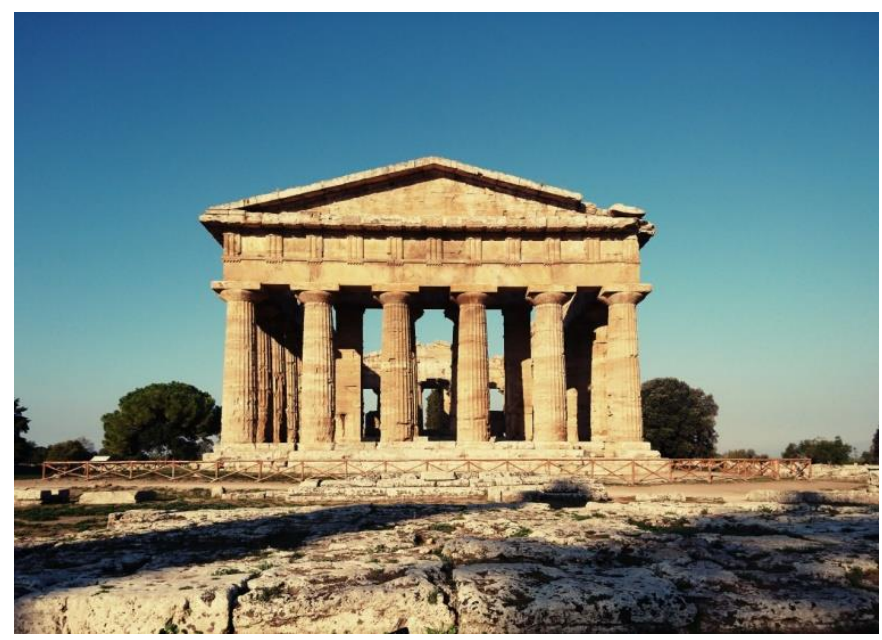

Figure 4. The view of the temple from the east side: the front façade. Copyright $(\subset)$ V. Di Marco (Source: Own work CC BY-SA 4.0. Link: https://commons.wikimedia.org/w/index.php?curid=71188205).

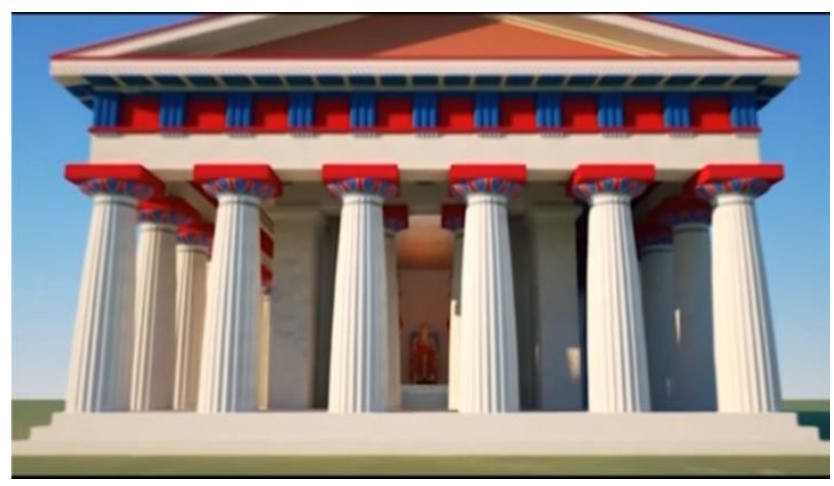

Figure 5. Chromatic reconstruction created for the exhibition "Colori nell'antica Paestum. Vita dei colori e colori della vita". Archaeological Museum of Paestum (Link at the video: https://www.youtube. $\mathrm{com} /$ watch?time_continue $=11 \& \mathrm{v}=\mathrm{Jl} \mathrm{Cdr} 5 \mathrm{~h} Y \mathrm{~b} 0 \mathrm{Q})$. Copyright $($ C) Archaeological Museum of Paestum.

The temple, built with local limestone, stands on a crepidine of three steps and has a cell with pronaos and opisthodomos, both in antis (sort of gates to access the temple) [78]. It is a Doric temple with six columns along its shorter sides and fourteen columns along its longer sides. The huge cella, accessed by four steps, was divided longitudinally into three naves, of which the larger central one, 
by two orders of seven overlapping columns. The entablature was formed by a smooth architrave and a frieze, made of sandstone, with un sculpted triglyphs and metopes. The whole structure had to be plastered and painted. The roof of the temple was supported by wooden beams and was decorated with polychrome terracotta.

It was probably dedicated to Hera, the bride of Zeus and main deity venerated in Poseidonia [79]. In front of the main (east) front of the temple there are the remains of two altars: one large, contemporary to the construction of the temple, and one smaller, i.e., a Roman addition (I century BC). Such altars are where ArkaeVision Archeo storytelling take place; for this reason, we studied their structure and dimensions (Figure 6).

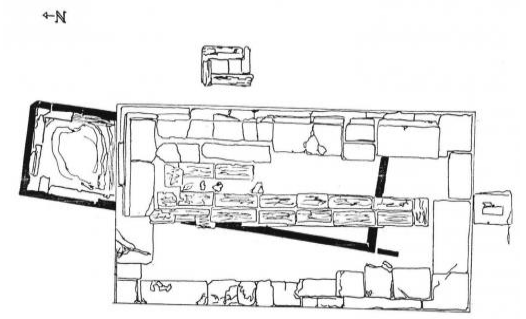

(a)

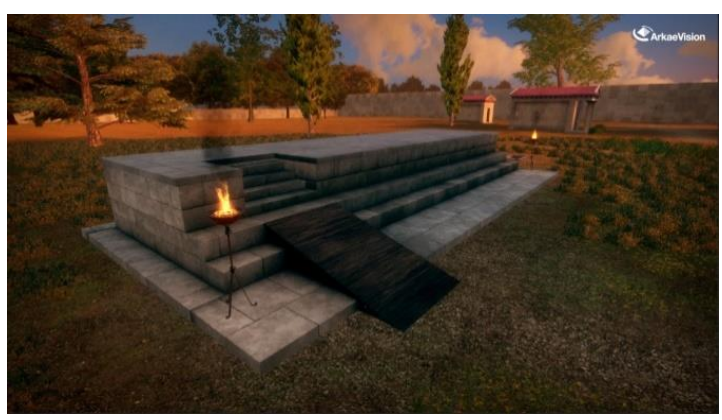

(c)

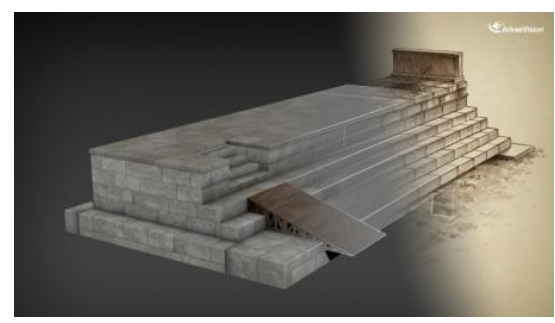

(b)

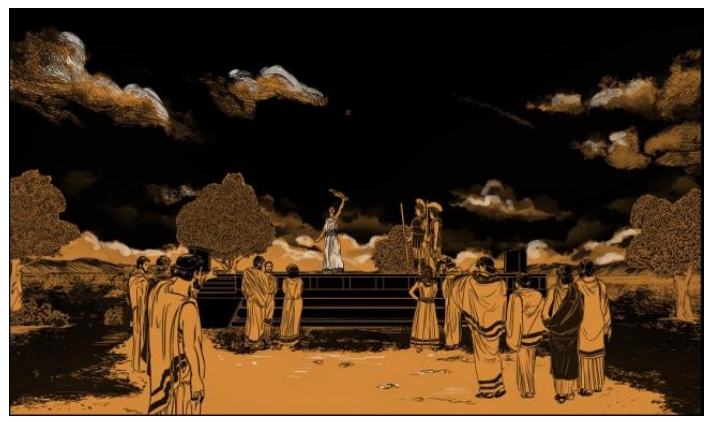

(d)

Figure 6. The I century altar BC in front of the "Temple of Neptune" or "Hera II" in different images: (a) (Source: Cipriani M., 1997. Il ruolo di Hera nel santuario meridionale di Poseidonia. In "Héra. Images, espaces, cultes. Actes du Colloque International de Lille (1993), (Coll. CJB, 15)", Napoli, pp. 211-225, ISBN: 9782918887201. doi:10.4000/books.pcjb.950) archaeological excavation, (b) digital drawing, (c) VR animation and (d) digital fiction. Copyright (C) Digitalcomoedia.

The altar was generally built in front of the main entrance of the temple; people looked at it from the outside of the temple and, for this reason, its shape was usually beautiful. Altars were made in such a way that the greatest number of people could attend the rituals.

The offerings and sacrifices were made on the altar; part of the offering in nature was burned on it, accompanied by libations. Sacred pits welcomed offerings and sacrifices for deities. Everything could potentially be sacrificed or dedicated to the god; some animals, such as the piglet and the horse, were reserved for the chthonic deities and Poseidon, while for others there was no strict distinction. Particularly solemn sacrifices of dozens of animals (hecatombs), generally oxen, were made on important occasions or to propitiate the divinity and the meats distributed among the citizens. The bloody offer was often replaced by fruits, bread or fruits with symbolic meaning (pomegranates, ears of wheat) [80].

Not only altars, but also sanctuaries. Objects of intrinsic or symbolic value were dedicated to the divinity, which present a considerable variety in the typology; the dedications could be public or private. The precious artifacts were kept inside the temple or in special buildings, the most modest probably under stoài or outdoors [81]. Votive objects were used by the ancient Greeks to thank the 
gods for granting them a wish. They could be of wood or textiles through simple statuettes of clay, marble or bronze statues, till arriving at the construction of entire buildings.

Some of these votive objects are used to characterize the VR environment of ArkaeVision Archeo.

\subsection{Sacredness, Devotion, Surrealism}

In the temple of Hera there was presumably a big statue of the Goddess whose care was in charge to a priestess - the only one admitted into the sacred area.

Both figures are reused as characters (active or passive) of the VR application with the function of revealing pieces of knowledge to users.

\subsubsection{Goddess Hera}

The cell of the temple was the house of the cult of the goddess Hera. Although we do not know the iconography, comparisons can be made with the votive statues and the testimonies on the cult of Hera in other locations [79,82]. Images from the first quarter of the fifth century B.C. represent her as majestic and solemn, often enthroned and crowned with the polos (a high cylindrical crown worn by several of the Great Goddesses); Hera may hold a pomegranate in her hand, symbol of fertile blood and death (Figure 7a).

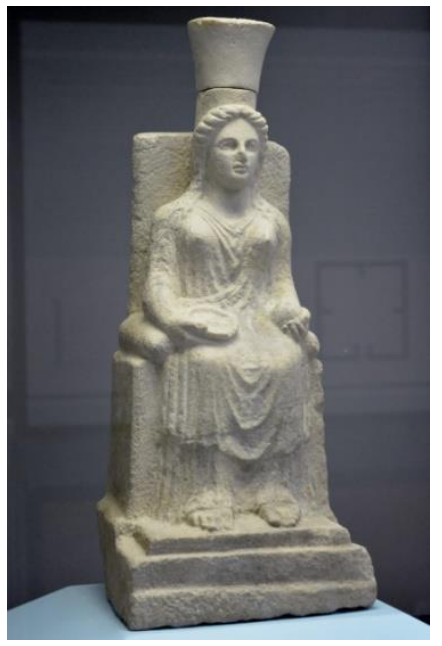

(a)

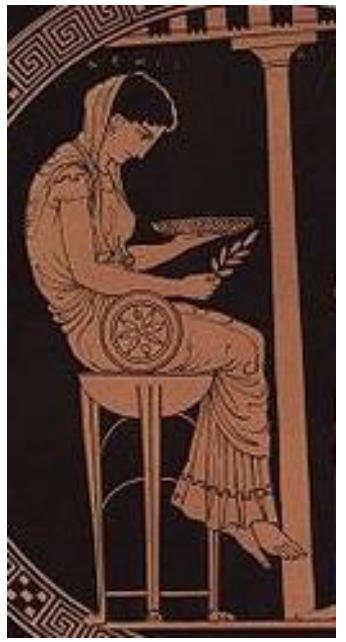

(b)

Figure 7. (a) Hera on the throne, with phiale on the right and pomegranate on the left (fifth century BC). Copyright (C) Archaeological Museum of Paestum. (b) Attic red-figure kylix of 440-430 BC. Work of the Painter of Kodros, depicting the goddess Themis, second holder of the oracle of Delphi according to Aeschylus. Copyright (C) Antikensammlung in Berlin.

Hera is generally considered the goddess of women, marriage, family and childbirth in ancient Greek religion; she is one of the Twelve Olympians and the sister-wife of Zeus. A matronly figure, Hera was the protector of married women and weddings. One of Hera's main features is jealousy and her vengeful nature against Zeus' numerous lovers. It is therefore not surprising that in her cult, men were often present during the sacrifices [83].

\subsubsection{Priestess of the Temple}

The young women consecrated to the custody of the cult, in ancient Greece, represent a phenomenon widely investigated by the history of religions; the priestess is mainly linked to the figure of the Pythia of the Oracle of Apollo, in Delphi (Figure 7b).

Greek priests and priestesses did not necessarily control the sacred knowledge of cults and rituals, but administered the places dedicated to these sacred actions. In this way, they also watched over 
the communication between men and gods, as mediators. Women were meant to serve the female gods and virginity was sometimes required of them. However, priests underwent certain rules for the duration of their office (e.g., chastity, food prescriptions) and were required to wear specific clothing according to the priesthood. There was no real priestly caste, but there were only priests of a specific divinity within a specific sanctuary.

There was a long debate, and still it is, about whether women were permitted to sacrifice or not [84]. It would seem that women were only able to conduct slaughtering of sacrificial animals in specific ritual contexts such as Thesmophoria [84]. In the Greek world, on the basis of iconographic evidence, two of the most important communicative tasks, guarding the temple and making the bloody sacrifice, were assigned exclusively to priests. The priestesses, as custodians of the divine house, in order to enable communication to take place, allowed then to enter the sanctuary while priests maintained a more active role in the ritual context with bloody sacrifice.

For ArkaeVision Archeo, having a leading female role who accompanies users along their journey is appropriate for the historical period and the solemnity of her relevant role.

\section{Virtual into Real. The ArkaeVision Project}

ArkaeVision is born out of a three-year project financed by the MISE, "Research and Development" actions, thanks to the Fund for Sustainable Growth- "Horizon 2020 Call". It was designed and developed by Digitalcomoedia, a company active on advanced digital content, together with the National Research Council (CNR), Institute for Technologies Applied to cultural heritage and Beyond Tech., an innovative startup expert in gamification.

ArkaeVision, in its broadest vision, is an integrated digital experiential platform that provides different ways of enjoying cultural heritage. It is composed by (a) an online portal, accessible from any mobile device (smartphone or tablet) and desktop-based system, (b) an immersive VR application (ArkaeVision Archeo, subject of this contribution) and (c) an AR application (ArkaeVision Art)—soon available at the Archaeological Museum of Paestum [85].

In general, the ArkaeVision experiential platform aims at:

1. introducing elements of spectacularization during the immersive VR experience recalling the attention of users on the archaeological sites and the objects exposed at Paestum;

2. developing new forms of enculturation based on the stimulation of intimate feelings and emotions, which will presumably help users see, feel and, finally, relive the past.

3. creating an infrastructure capable of expanding the museum supply, enhancing its visibility, putting in connection places with artifacts while promoting participatory and social dynamics.

In (b) ArkaeVision Archeo, the experience is designed to involve users in a circular and iterative way. It starts when they first consult the project's web portal and the pages dedicated to the archaeological site and/or the museum. ArkaeVision Archeo can be used once the users arrive at the museum, after having booked an explorative session (Since the web portal has not been optimized yet, the VR experience can be booked directly at the Archaeological Museum of Paestum - updated April 2020). Users can virtually visit the temple dedicated to Hera II of Paestum, in the first half of the fifth century $\mathrm{BC}$, wearing the HTC Vive and using hand controllers; here they can interact with a digital actor, the priestess Ariadne, who will guide them virtual tour presenting the beliefs, the values and the ancient of ancient population of the Magna Graecia city (Figure 8). The experience is completed when they conclude the VR experience; users are profiled thanks to an automatic monitoring of their actions during VR exploration. The data collected allows the UX to be adapted to their needs and interests for future occasions, unlocking new contents or accessing hidden objects and places. 


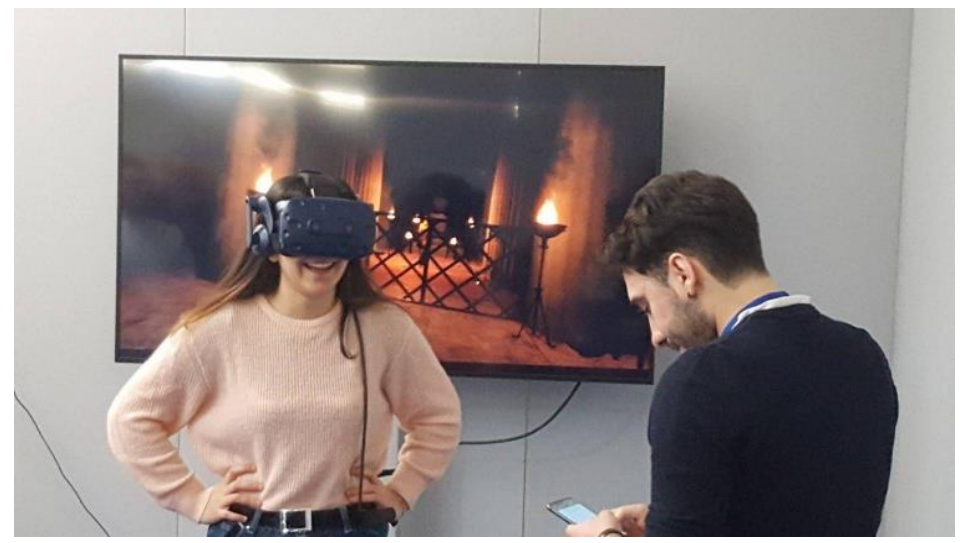

Figure 8. A visitor wearing the HTC Vive to virtually explore the temple of Hera II. Copyright (C) Digitalcomoedia.

Users can take advantage of two explorative modalities: an emotional and semi-guided visit, where events and facts evolve in the storyline catching their attention and pushing them to follow the visit; in this phase, they can do some actions, like walking in VR, watching around, choose what to explore, but always guided in the experiential pathway by the digital actor; a didactic and free exploration, where the users can choose which information to deepen, accessing specific points of interest or 3D assets, plan what to do and where to go in VR exploration; here they are alone with no guide.

The gamified perceptive storytelling of ArkaeVision Archeo takes place in the area referable to the temple of Hera II, located (in reality) on the occidental side of the archaeological park of Paestum. The temple rebuilt in 3D, the surrounding landscape, vegetation elements and nearby architectures are depicted following the vedutismo pictorial style of the IX century.

The playable area corresponds to the interior of the temple's naos, specifically the frontal and side colonnade and a modest external section; then, the exterior of temple, including a sacrificial altar and a lateral structure called donari. Inside the temple a digital character guides the users for the entire duration of the experience, interacting with them and making them a protagonist of the narrative (Figure 9). During this story, the users have the opportunity to deepen the myth of Hera, know the problems of the attribution of the temple and understand its ancient uses through the observation of a ritual performed on the external altar.

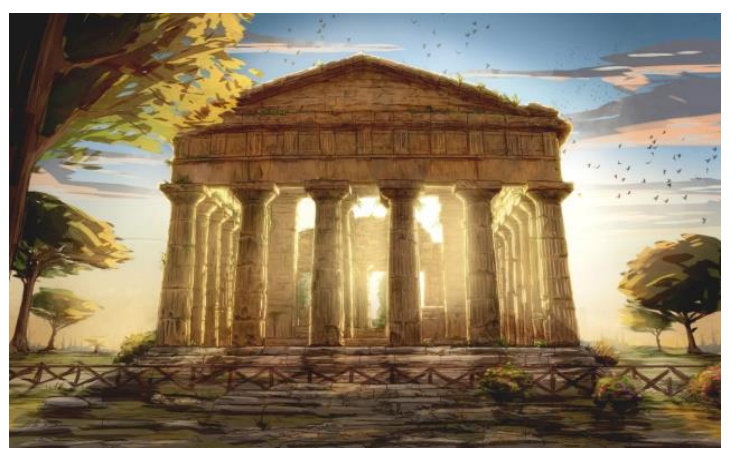

(a)

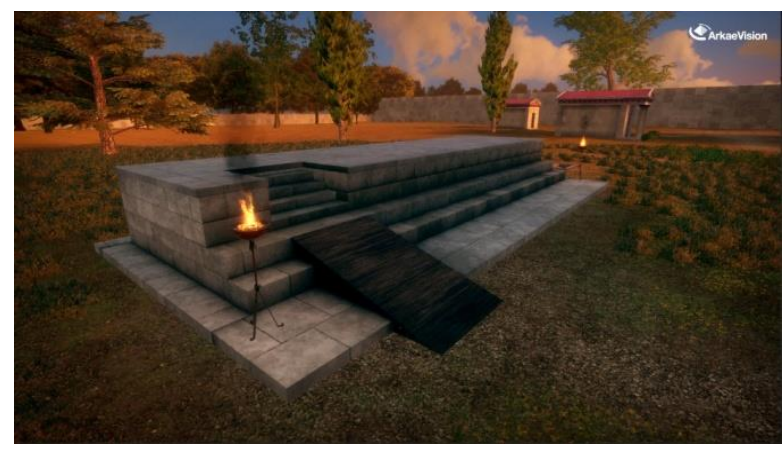

(b)

Figure 9. Screenshots taken from the VR application of ArkaeVision Archeo: (a) interior of the naos in $500 \mathrm{BC}$ with the priestess Ariadne and (b) sacrificial altar in front of the temple. Copyright (C) Digitalcomoedia. 
ArkaeVision Archeo requires users to wear the HTC Vive viewer to live a transition from the current scenario of contemporary Paestum's archaeological site to 3D reconstruction of the ancient Poseidonia. Users are also asked to use hand controllers to guide the experience.

Scenography, art and traditional filmic direction were integrated for the digital reproduction to represent the atmosphere of Poseidonia in the fifth century BC. An experience in History cannot be separated from truthfulness and for this reason a referencing study on architectures, characters and lifestyle was done to faithfully reproduce the atmosphere of the past. In addition to the scenography and to the architecture of the archaeological site, characters have a great relevance too. In ArkaeVision Archeo, the main character is Ariadne, the priestess of the temple of Hera who drives visitors to the discovery of places and objects of the fifth century BC. These aspects are further deepened in Section 3.3.

\subsection{ArkaeVision Archeo: Game-Oriented Components}

The main components of ArkaeVision VR application relate to the interactive exploration set upon a precise storytelling and to the game-based activities that users can accomplish during the VR experience [86,87]. It is important to explain that ArkaeVision is not properly a serious-game and it does not fully exploit the features of the gamification; yet, it is intended to influence people's natural attitude towards the socialization, learning, achievement, self-expression and fun; moreover, it partially follows game design elements. Nevertheless, authors refer to the framework "learning mechanics-game mechanics (LM-GM)" [88] which considers serious games as an agglomeration of two types of mechanics, namely those related to learning (LM) and those related to gaming (GM). They also take advantage of another framework "activity theory-based model for serious games (ATMSG) which can be considered an evolution of the LM-GM model [88].

Relying upon these assumptions, ArkaeVision Archeo can be described through its (a) game-oriented mechanism, which allow users to get to know the VR context and explore it; the game-oriented strategies that users can take advantage of, to know more about the historical period, environment, rituals and beliefs; the game-oriented objectives with the purpose of entertaining users, but especially educate them (experiential learning-see Section 1.1).

Deepening on the general infrastructure of ArkaeVision Archeo can be read in [85].

\subsubsection{Mechanism}

The exploration of the ArkaeVision VR environment mainly refers to the mechanism of information accessing [62]: ask/answer questions, see/listen to/read information. Users can listen to the guiding voice, meet the guiding character and follow her along the explorative path; moreover, they can access extra information, reading them in superimposition in the immersive visualization or deciding to skip them, by clicking on the hand controllers provided with the viewer. Content is also diversified by type of user (user profiling at a time prior to VR exploration - children, expert, common visitor-when a person books the experience on the web portal) and by style of narration (folk tale, in-depth narration, general narration). In ArkaeVision Archeo the story is overwhelming, appealing and captivating.

\subsubsection{Strategies}

The virtual exploration of ArkaeVision Archeo relies upon a series of game-oriented strategies which help users to follow the storyline that unfolds dynamically, depending on their choices, but still univocal (the ending is the same for all users). These strategies are:

- Help. Digital actor's assistance, tips, initial tutorial, warning messages are presented in order to assist users during VR exploration and make feel them as autonomous as possible.

- $\quad$ Storytelling. Cut scenes, leading stories, parallel stories, deepening and visual metadata are presented in order to support users' comprehension of what they see, feel and "touch" in the VR environment. 
- Measuring goals. Achievements, performance records, score, success levels, timing are recorded by the system and visualized by users during VR exploration, in order to motivate them to proceed with the story. Such goals are useful in the further phase of ArkaeVision Archeo experience, when users access the web portal: they can consult the explored VR areas, the listened stories and see what they have missed [85].

- Scoring. Quizzes can be found during VR exploration; they positively influence the information retention, "forcing" users to recall at their attention data just acquired and elaborate them so to answer the quizzes [89], by using the head controllers. These quizzes are set in some points of VR exploration to stimulate users' attention and memorability; related scores can be consulted when users access the ArkaeVision web portal and they can be useful to measure the level of deepness of the experience done, and the quantity and quality of information collected.

\subsubsection{Objectives}

In ArkaeVision Archeo, the exploratory experience [90] allows users to follow the storytelling divided into progressive steps and guiding them till the end. The latter brings the users back to the starting view of VR exploration-a sign that they have finished the story and accomplished all the required tasks. The time passing from the start to the end of the exploration allows users to get a score in a ranking scale, which can be consulted in the ArkaeVision web portal, which somehow identifies users' ability (Did they perform as good/agile/fast/correctly by answering to the questions of VR exploration?).

Hence, two goals of the immersive exploration of ArkaeVision Archeo relate to:

- Narration. Completion of a narrative-based challenge, create/discover a narrative node, know the story and reach the end of the VR experience.

- Interaction. Users follow the narration thanks to the guide, the priestess Ariadne, who poses questions, quizzes and push them to specific areas of the VR environment. Users can do what they are require to, by addressing the gaze in the right direction or using the hand controllers (point-and-click technique).

\subsection{ArkaeVision: Design of the Immersive Virtual Experience}

The ArkaeVision Archeo experience is limited to $15 \mathrm{~min}$ and users are free to take off the viewer whenever they want. However, the storyline flow, conveyed by Ariadne's verbal interaction with the users, is purposefully conceived to stimulate them in completing the exploration. The experience is designed to be done by one person at a time.

More in detail, ArkaeVision Archeo takes advantage of some gamification elements both in the storyline (by means of artifacts to be found like in an adventure game) and for the interaction modalities (similar to those of role-playing games) as a combined approach to maximize users' involvement and to actively stimulate them to deepen the knowledge [64,91].

Users can play either the aforementioned experiences, in sequence or just one by one. Before the experience begins, indeed, it is possible to configure the system to enable both options either by means of the museum personnel or even automatically, based on the information previously provided by users.

\subsection{ArkaeVision: Aesthetics and Visual 3D Modeling}

ArkaeVision Archeo is designed to provide a strongly visual-oriented experience; consequently, both VR environment and characters was developed with the utmost attention to visual realism and verisimilitude to the aesthetics of ancient Poseidonia-Paestum. This challenge involved the usage of advanced visual and programming techniques optimized to run on the chosen hardware platform. 


\subsubsection{Modeling}

The 3D modeling process behind ArkaeVision Archeo is based on a complex pipeline of work well consolidated in the CG industry [92]; the actual polygonal modeling follows the creation of visual references made by means of hand drawing performed by graphic artists.

After a number of reviews aimed at refining the drawings to better capturing and describing the essence of the environment and of the main character, polygonal modeling with subdivision surfaces was used for translating the drawings into corresponding 3D models compliant with the platform requirements (in terms of polygonal budget assigned to each entity as well as to the entire virtual environment) [93]. In the prototype creation stage, the first visual proposal for both the Ariadne character and the general appearance of Paestum's surroundings (Figure 10) was sketched by hand and progressively refined until they matched the desired visual mood.

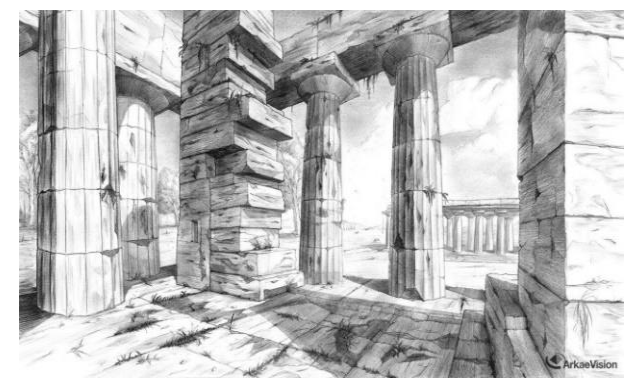

(a)

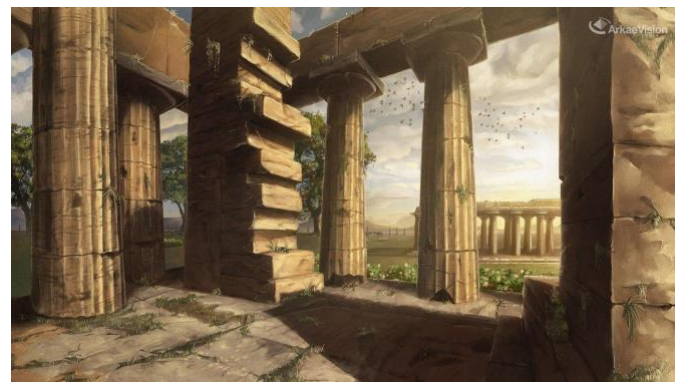

(b)

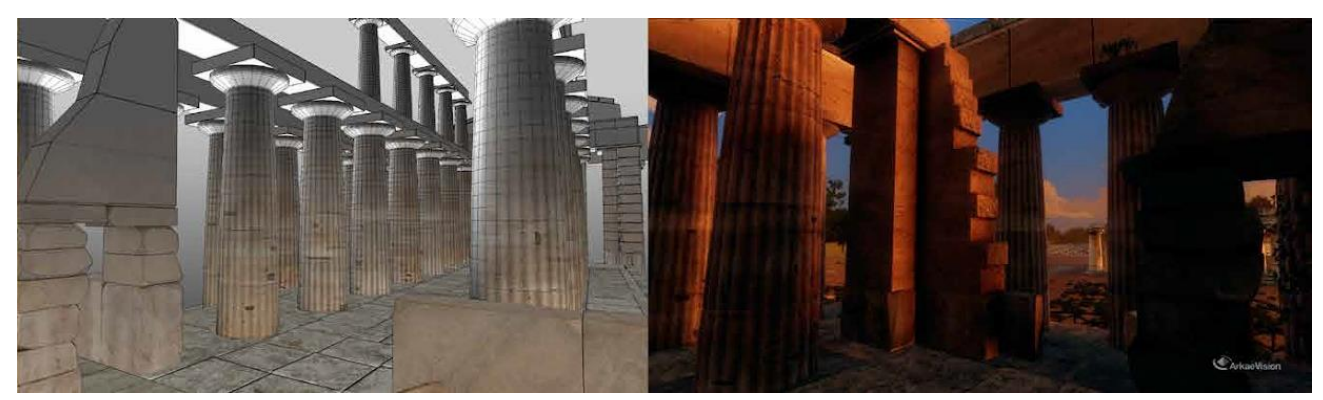

(c)

(d)

Figure 10. Shots aimed to study how to reproduce the atmosphere of the past: (a) first a black and white drawing, (b) a colored version, then (c) a digital canvas till arriving at (d) the 3D model. Copyright (c) Digitalcomoedia.

This first approximation was therefore the starting point for the 3D modeling stage which was also characterized by a set of requirements such as:

- $\quad$ the exclusive usage of polygonal modeling techniques instead of other more CAD oriented methods exploiting parametric surfaces (e.g., NURBS/Spline modeling);

- $\quad$ no subdivision surfaces used to increase the polygonal resolution;

- $\quad$ no more than 64,000 vertices allowed for each single component;

- $\quad$ UV coordinates ranging between 0 and 1 (no UDIM UV Mapping supported);

- $\quad$ low textures number with atlas-based texture management approach;

- $\quad$ hierarchically linked meshes according to topological components arrangement, enabling visually realistic motion through kinematic chains;

- compliance to conventions regarding labeling of local axes and their positive direction.

The resulting models underwent an accurate rigging and skinning stage, aimed at achieving the most realistic and lifelike behavior of character's joints and facial motion. In particular, angle-based 
joints shaping allowed to optimize the aspect of critical joints such as clavicles and elbows (which are naked in the Ariadne model) when approaching high angular values. A final step of 3D paint-based vertices deformability has also been performed to further refine the dynamic aspect of the character.

\subsubsection{Characters}

The production phase of the digital character exploited the most modern techniques made available to the CG artists [94] — as highly detailed 3D sculpting, high dynamic range images, particle systems, motion capture, just to name a few-to achieve a reliable result and with a well-defined visual personality.

Starting from the pre-production artworks, a digital sculpting version of Ariadne was created, which was subsequently retopologized (which means redefining the mesh of the 3D models at a lower resolution) and optimized in terms of their topology and polygons count for real time rendering. Even the dress was generated through software fabric simulation, to achieve high levels of realism.

To create the digital character, motion capture and lip-sync cinematographic techniques were used. Through a dedicated hardware, the movements and the acting of the performer who played Ariadne were captured. Performance capture has allowed to adequately convey the acting and the director's intentions to the digital character.

The realization of Ariadne, went indeed through three phases (Figure 11):

- Philological analysis phase: the development of digital actor representing Ariadne required an accurate research and study's phases to characterize a well-defined personality with an identifiable behavior in the historical era.

- $\quad$ Pre-production phase: creatives and developers studied the features of the character, aimed at accurately identifying the aesthetic characteristics of the digital actor from an ethnic/anatomic point of view as well as for what was related to its aesthetic details (dress, jewelry, hairstyle).

- $\quad$ Acting and directing phase: last phase was the Ariadne's characterization from the acting point of view. Phrases, movements and expressiveness were minutely analyzed and appropriately interpreted by the actress who played the part, subsequently transferred, through Performance Capture techniques, to the CGI character.

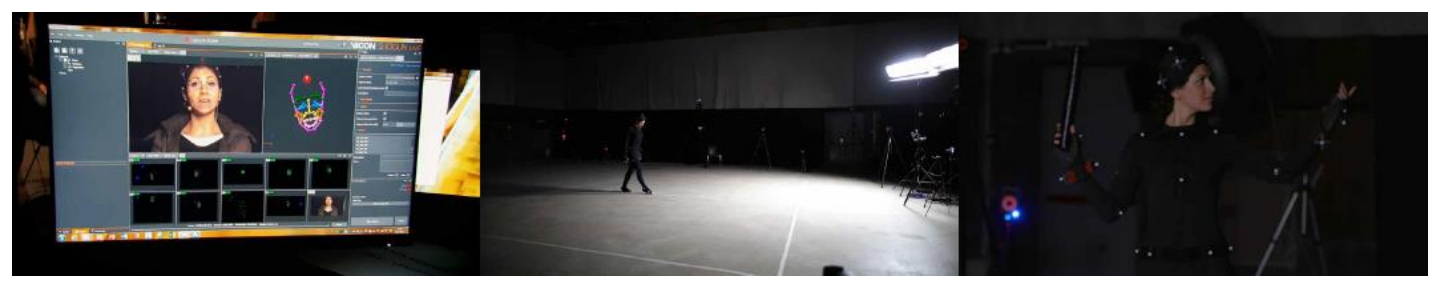

Figure 11. Sequence of images of the performance capture phases. Copyright (C) Digitalcomoedia.

Here below some visual examples of the pipeline of work done for ArkaeVision Archeo, especially for the Priestess Ariadne (Figure 12).

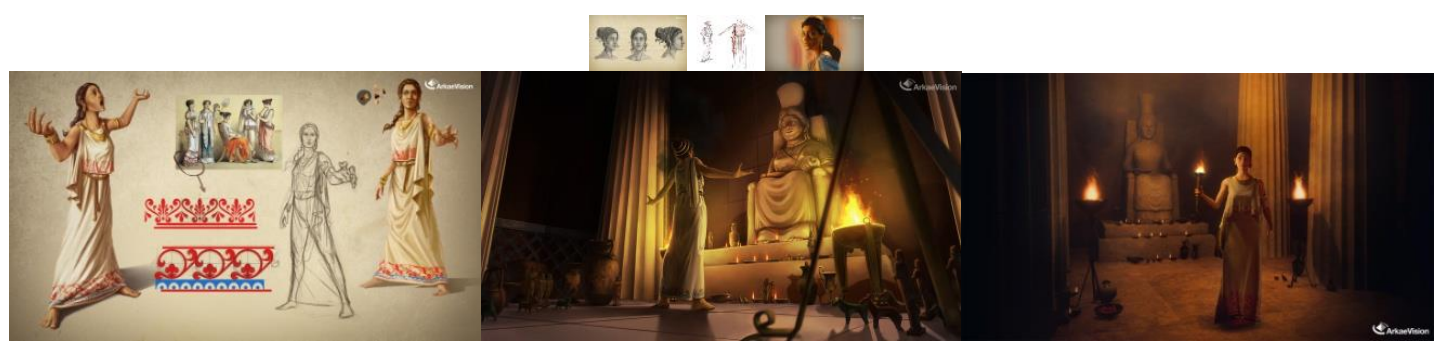

Figure 12. Sequence of images showing how creatives and developers conceptualized the character of the Priestess Ariadne from scratch to real-time 3D models. Copyright (C) Digitalcomoedia. 


\subsection{ArkaeVision: Learning Analytics}

The theoretical framework, on which ArkaeVision Archeo is based is presented in Sections 1 and 1.1 of this contribution. In general, the main research questions relate to how supporting the activation of curiosity in users and how to maintain attention and interest in order to let the learning processes to take place; moreover, authors want also to understand how to use emotions to develop new forms of narration at the museum and help users remember them more easily.

The experiential model of Kolb and Freitas [6] stays at the basis of the VR application (Figure 13), useful to investigate (a) the level of abstraction reachable through a technological-mediated immersive experience. Such a level of abstract may help users to feel immersed into the virtual world of ancient Poseidonia thus enabling the meaning-making process to happen.

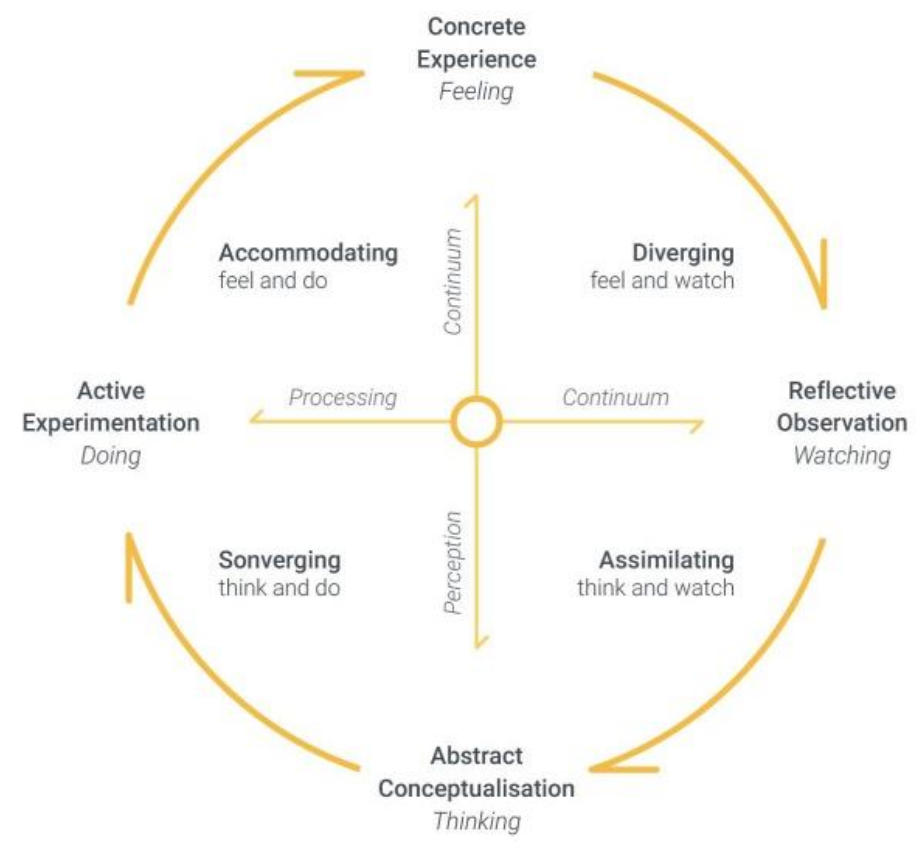

Figure 13. Elaboration of the experiential model of Kolb and Freitas (Source: Arnab S. et al., 2015. Mapping learning and game mechanics for serious games analysis, 2015).

Bloom's Taxonomy is taken as reference too [7-9,95]; it generally defines the steps of any learning process and, for ArkaeVision Archeo, it serves to evaluate (b) the learnability and (c) memorability of the gamified perceptive storytelling. Following the domains in which Bloom subdivides the experience—cognitive, affective and psychomotor—we have specifically studied (Figure 14):

- The level of users' attention, memorization and elaboration [8,96]; these three, at the end of the project, should lead to a clearer vision of the potential inherent in the immersive VR application regarding:

- knowledge acquisition (understanding and learning)

- acquisition of certain skills based on newly acquired knowledge (experience)

- $\quad$ knowledge retention (storage and processing)

- $\quad$ The receptivity of users, i.e., the faculty to perceive and beware of specific visual inputs, verbal suggestions and, etc., scenario after scenario, along the VR exploration [7].

- The users' emotional response, i.e., the reaction to environmental stimuli, so to respond in a condescending or spontaneous way [7].

- Finally, on a psychomotor level [97], the basic movements that users perform are considered significant as well as the dexterity of the movements, i.e., the ability to adapt to a virtual or alternative scenario. 


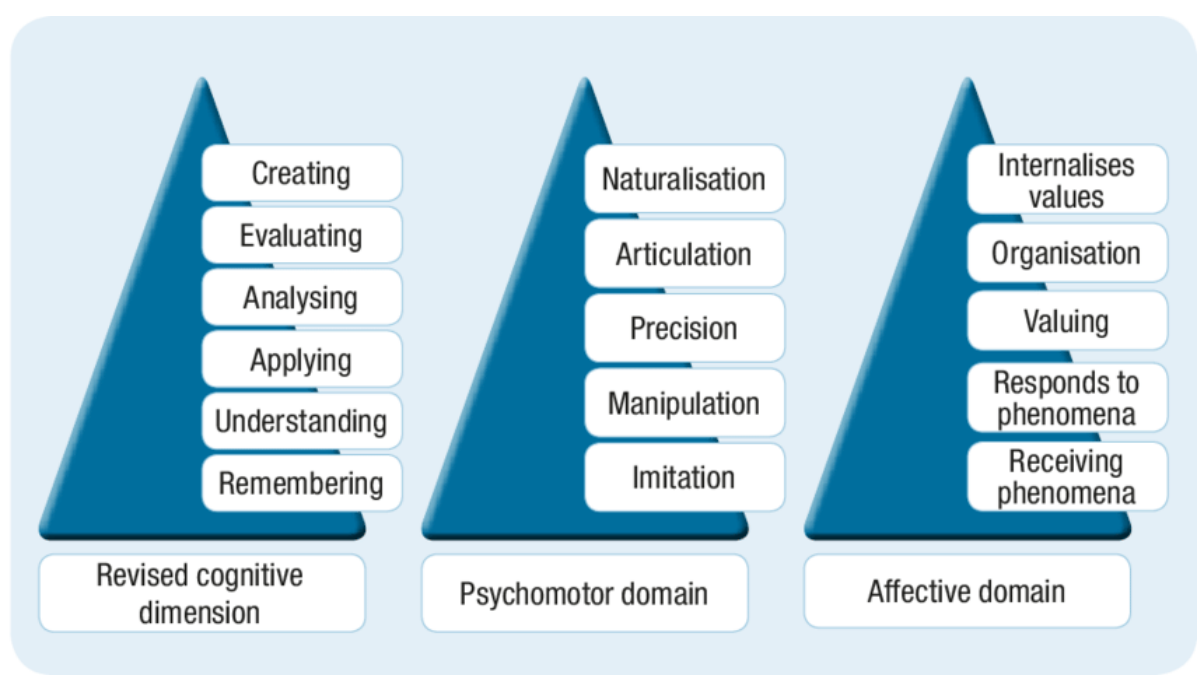

Figure 14. Bloom's taxonomy: cognitive, psychomotor and affective domains (Source: Pouliou A., 2019. Cedefop (2017). Defining, writing and applying learning outcomes: A European handbook. Luxembourg: Publications Office. 10.2801/566770).

Referring to learning analytics, authors have carefully selected mechanisms, actions and tools as it follows.

\subsubsection{Learning Mechanism}

In ArkaeVision Archeo, users ideally follow a path of gradual discovery of the cultural environment (the temple of Hera II and the city of Poseidonia); they approach the sequence of events with their actions and choices to obtain a "reward": an understanding of the effects of their narrative choices on the general storyline and the continuation of the narration up to the epilogue of the story. The users must carry out limited actions during their exploration, like reflective and motor's decision-making.

The mechanism (or paradigm) here employed is therefore, Action/task: one or more specific task that users perform in the VR world in order to continue the story and/or get a reward. A task could be a problem to be solved, an exercise to be carried out or even a physical activity or mental process to be undertaken. In ArkaeVision Archeo, for example, users are asked to choose a votive object to be offered to the Goddess Hera, selecting the right one, in order to do not incur in Hera's curse.

\subsubsection{Learning Actions}

The memory of each individual is influenced by multiple factors and produces a plastic record that can change depending on the positive or negative experience that generated it and from the time elapsed from when we experienced it to when we recalled it.

In the case of ArkaeVision Archeo, the memory of the VR experience is indeed influenced by the users' ability to understand, analyze and evaluate the environmental conditions and, consequently, decide and act, how to proceed with the exploratory activity. The memory, contextual and a posteriori, passes necessarily from the understanding of what the users are experiencing, from the storage of the emotions and the readability of the proposed contents.

Examples of learning actions in the VR application are when users are asked to imitate the Priestess Ariadne to extend their greetings to the Goddess in a proper manner; or, to recite the Pray to the Stars as Ariadne does. Moreover, users have to select some votive objects to be gifted to Hera in the donari by distinguishing the correct ones among a bunch of items; or, users have to deduce that they cannot go closer to the Goddess' statue through the words of Ariadne and the "physical" limits that the system poses. 


\subsubsection{Learning Tools}

ArkaeVision Archeo uses various learning tools:

- Information graphics-art, graphics, illustrations, drawings, 3D effects;

- Textual information-metadata of 3D elements (age, provenance, dimensions,), analogies, definitions, historical facts, list of activities to be carried out;

- Multimedia—animation, cinema, speeches, videos, 3D models, evocations;

- Problem-solving—narrative nodes and crossroads, puzzles, challenges.

These are located throughout the experiential arc of the VR exploration and they are related to graphics (360 panoramas, pictorial style of 3D modeling, etc.), animations (motion capture of the virtual guide Ariadne in order to make her appear "natural") and information units.

Some examples are the visual aspect of the Temple of Hera, reconstructed in the fifth century B.C.--users may make comparison between what is left today and this ancient view; 3D objects like vases and small votive statues are supplied with information set aside of the visualization (so called "3D spatialized metadata"); changes in the pictorial style of images can be seen to differentiate the main storytelling from the side stories.

\section{UX Evaluations}

In order to probe and test the research questions of ArkaeVision Archeo, it was necessary to conduct User eXperience Evaluations (UXEs).

Two occasions were selected to carry out such analytic activity. A first UXE was planned in November 2018, when ArkaeVision Archeo was first released to public in its demo version. The occasion was the Archeovirtual exhibition (www.archeovirtual.it), organized by the CNR at the Archaeological Museum of Paestum. A second UXE took place in February 2019 during the TourismA festival (https://www.tourisma.it) in Florence and the VR application was in its final stage of development.

The two occasions had some points in common, but also differences which brought authors to adjust the UXEs in terms of conduction and logistics. Nevertheless, given the importance of having comparable data and similar methodology, evaluations fulfilled a precise scheduling and evaluative tools.

In Paestum there were mainly a young target such as schools, universities, families and young tourists, given the type of the event (more didactic and formative); in Florence there were professionals, experts in the field of $\mathrm{CH}$ and $\mathrm{DCH}$, private companies and families due to conferences, workshops and exhibition areas planned in the festival. For such a reason, targets were different, and results could be unbalanced. To overcome such issues, the evaluative tools (see Section 4.1) were studied and compiled with the assistance of cognitivists and pedagogists of CNR in order to have precise questions, specific tasks to accomplish and, at the same time, a quite large grid of reference for evaluating the data collected according to ages, cultural background and technological alphabetization.

Both in Paestum and in Florence there was enough space to live the experience quite comfortably; the dedicated area was indeed of about $6 \times 6 \mathrm{~m}$ with the following equipment (Figure 15):

- An interactive area of about $3 \times 4 \mathrm{~m}$ where users can physically move, indicated by a PVC black/blue carpet, a web tensioner, tables and chairs;

- A workstation dedicated to ArkaeVision Archeo with PC, Monitor 55 inches, HTC Vive viewer and trackers;

- A remote station for assistant/technician useful to guide users throughout the experience with PC and Monitor-27 inches. 


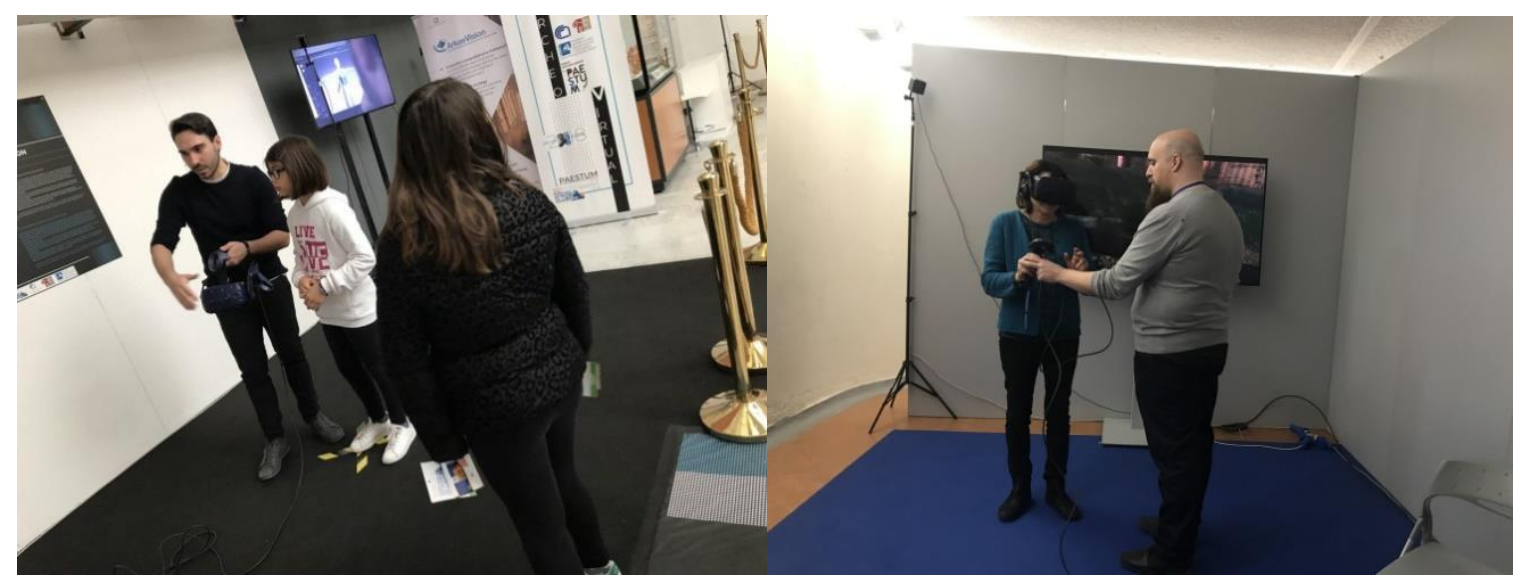

(a)

(b)

Figure 15. Pictures of two evaluative sessions: (a) during Archeovirtual exhibition, Paestum and (b) during TourismA, Florence. Copyright (C) CNR ISPC.

The affluence of people was quite the same on both occasions and a high number of data were collected.

\subsection{Goals and Methodology}

The reasons for evaluating ArkaeVision Archeo are largely presented in Section 1.1. and Section 3.4. They refer to three main goals:

A. The effectiveness of the way of experiencing the content-by means of an immersive viewer and hand controllers. The authors want to understand if the system is usable and the quality of users' interaction-as immediately and natural as possible.

B. The emotional component of VR interactive exploration. Emotions in ArkaeVision Archeo should help the learning process to be activated $[98,99]$ by analyzing the narrative nodes and how they were stimulated, how long users listened to them and which one they have selected. This information may lead authors to understand any correlation between time spent with the VR application and emotive state of users, level of emotional involvement and quality of information remembered, type of actions performed, and type of information remembered.

C. The involvement of users through a gamified perceptive storytelling. It is true that to increase the user's engagement gaming-like techniques are advisable: choose a goal to be reached within the virtual exploration, such as moving to the next level of the story; unlock some narrative nodes; meet a virtual character like Ariadne in the temple ... these cause a strong motivation in the users, who are very effective in focusing and concentrating on completing a task and bringing self-confidence. Such kind of experience in ArkaeVision Archeo should therefore encourage users' content understanding.

As a methodology, the multi-partitioned analysis was followed-as a proved valid framework for conducting evaluation in the field of technology applied to $\mathrm{CH}$ [100]. It is generally made up of three assessment tools used according to a predetermined schedule and a specific operating method. These tools allow to get a more in-depth view of user profiling and experience. For ArkaeVision Archeo only two of these was used, because of the state of-the-art in the development at the moment of the public exposition. The evaluative tools were:

- Observation: it is one of the most used at the beginning of each evaluative activity, although it is not always easy to conduct [101]; it is extremely useful as it provides fertile ground for the first considerations on users and technologies and for constructing the conceptual map for the 
investigative comparison of the results obtained by direct survey tools. Observations are not used only at the beginning of the evaluation, but also during the user experience.

- Questionnaire: it is essential to probe the basic knowledge of each user to identify the needs and expectations, recognize the attitudes, gestures, movements and comments [102]. The questionnaire is widely used in research and it is built upon the goal to be pursued (type of questions, modulation of sentences, language's level), and the function it must have in the context of the project to be evaluated (usability test or demographic interest, customer satisfaction or cognitive learning, etc.); users can fill in the questionnaire independently, with a certain margin of expression.

In ArkaeVision Archeo, the UXEs involved therefore two types of research, quantitative and qualitative, different both in the operating methods and for the used tools.

In quantitative research, the reflection on collected information is based on a large number of questionnaires; the percentage calculation of the answers returns a general image of the trends linked to the investigated topic [10,100]. Quantitative research is indeed presented through charts and graphs; it can be used to establish generalizable facts about a topic. In our case study, data collected were:

- Demographics. Age, gender, provenance, educational background, technological alphabetization, profession; preferences on the type of cultural visit (alone or in group; for working reason or with families); preferences on the type of technological device used; time spent with such a device; reasons to visit cultural site; average amount of budget assigned to cultural experiences.

- User experience. Usability, efficiency and performances of the product; users' preferences about the aesthetical features of VR; timing of VR exploration; users' sense of immersion in the VR environment; users' comfortless using the viewer and the hand controllers; intuitiveness of functions and their practice; naturalness and practicability of the interaction modes, any sense of tiredness during VR exploration; any locomotion effect.

- Emotional sphere. Overall sense of embodiment with the VR world, sense of involvement, preferences of the VR application (style, colors and general atmosphere, storytelling, interaction with character, sense of immersion).

- Learning outcomes. Users' memory about the exact period of time traveling, the name of the goddess in the temple, the name of the Priestess, the number of columns of the temple, the genealogy of the Goddess, the correct votive objects loved by the goddess and why, the myth of the Milky road, the place where the sacrifices happened, who could participate at these sacrifices.

- Dissemination. How users image the appliance of the VR application in museums or schools, if users would suggest this type of experience to others, what they would better and what they would change at all, how much would they pay for such a VR immersive experience.

On the other hand, in qualitative research, the descriptiveness of the data collected is examined, the words and their meanings. This type of research enables to gather in-depth insights on topic that cannot be simply unveiled through numbers. Once collected, the information units are crossed, compared and grouped by similarity or divergence. In our case study, the adopted tools are observations and open questions in the questionnaires. Data coming from this type of analysis related to impressions and comments reported by users regarding:

- User experience. Relationship between users and the technological tool; naturalness and intuitiveness of the viewer and the controllers' usage, naturalness of interaction and gestures required by the system; any sense of satisfaction in reaching goals into VR exploration; any sense of curiosity and interest to proceed with the experience.

- Cognitive sphere. Difficulties in facing challenges and tasks to be accomplished during VR exploration; issues related to the storyline; issues related to connections between items, stories and tasks to be accomplished; preferences about aesthetics of images; any sense of realism, any parallelism with users' everyday life. 
- Emotional sphere. Overall sense of embodiment with the VR world, sense of involvement, emotions felt during the VR experience and why (free answer), what users liked the most and what users disliked of the VR experience.

Moreover, with observations, the operator recorded the users' behavior during VR exploration, without interfering with their decision-making process and actions. Data collected related to:

- Users' level of comfort. Users' behavior, gestures and actions in relation with the viewer and the hand controllers; any locomotion effect.

- Users' level of attention. Users' capacity to follow the storytelling and the "spatial metadata" appearing in some places of the VR environment; directions where users addressed their attention; time spent listening to the stories; remembering of actions to be performed to accomplish certain tasks or interactions.

- Verbal and non-verbal communication of users. facial expressions, gestures, virtual proximity, virtual touch, eye contact. The operator could take notes of these aspects by direct observing the users and also the monitor where users' head movements were registered. In such a way, it was possible to understand where they were looking at, any indecision in the movements or actions.

For the quantitative data, we produced graphs and charts using Excel files; in some cases, we also cross checked results coming from a group of questions, trying to correlate, for example, users' technological alphabetization and background knowledge with learning outcomes; users' preferences on cultural visits with answers about dissemination and overall satisfaction; users' experience with learning outcomes and also data coming from observations.

For the qualitative data, we first tried to divide the answers to open questions (of the questionnaire) into categories, in order to better highlight the tendency among users. Similar concepts were aggregated into the same category. An example is the question "Why did you say to feel immersed in the VR experience?". Answers like "It was real", "The experience was realistic", "The movements were plausible, true", "For the reconstructive fidelity of architectures", and "For the reconstructive coherence" were all grouped. In parallel, we tried to read the answers according to the users' profile and their whole experience-trying to detect any possible incoherence between what they said and how they behaved during the VR experience. Afterwards, percentage calculation of the incidence of the same items in each category was made, as well as for all identified categories. The same was done for both locations-trying to compare coherent and similar categories. Answers that could not be grouped were left aside and taken into account at the end of the process as collateral comments. Qualitative results were further compared with observations made by the operator, who cross referenced users' profile with their common behaviors and the latter with the learning outcomes. Operator also tried to find a common line between quantitative results and the related identified qualitative category; an example is the comparison between the time spent by users trying to accomplish a specific task during VR exploration (data from observations) and users' direct feedback about usability and intuitiveness of the system to suggest what to do (data from questionnaires-closed questions).

This pipeline of work did not refer to any established framework for quantitative and qualitative analysis. We adapted techniques and best practices surveyed for other projects $[15,21,100]$.

\subsection{Logistics and Conduction}

The interactive area of ArkaeVision Archeo, both in Paestum and Florence, was overseen by a UX evaluator and a technician/assistant. The former took care of the evaluation, welcoming users and explained them the importance of such activity and how it was organized; UX evaluator followed users along the evaluative process and assured that the conduction and the data collected were consistent and valid. The latter, instead, was dedicated to the VR application, welcomed users in the interactive area, explained them how to wear the HMD and provided them the assistance for all the duration of the immersive experience. Generally, the UX evaluator was a member of the CNR, while the technician was part of the Digitalcomoedia. 
As largely explained in [85], the conduction in the UXEs foresaw that users freely approached at the multimedia installation. They were first asked to play with ArkaeVision Archeo, according to their will and availability; they were also informed about by the UX evaluator about the scope of the research, the conduction and the timing. Once users accepted, they could wear the HMD and the hand controllers, always having the technical operator aside, in order to recall his attention in case of need. In parallel, UX evaluator started annotating users' behaviors and comments filling a pre-defined template. Once users finished the virtual exploration, they could join the UX evaluator to answer the questions related to the storytelling and the overall usability. Almost all users filled the questionnaire template by their own; in a few cases (6), when the users were unable or old, UX evaluator conducted a sort of guided interview, questioning them and noting down their answers. UX evaluation templates was the same for all users and the observation protocol was progressively assigned to a specific code number, in order to match it with the users' related questionnaire.

The arranged materials and logistics followed the below numbers, in both venues (Table 1):

Table 1. Data collected in two occasions of evaluation.

\begin{tabular}{ccc}
\hline & Paestum & Florence \\
\hline period of the year & 15-18 November 2018 & 21-24 February 2019 \\
\hline occasion & Archeovirtual & TourismA \\
\hline total days of evaluation & 4 & 4 \\
\hline time of VR experience & 7 & 10 \\
\hline time of UX session & 15 & 23 \\
\hline average age of users & 31 & 38 \\
\hline observations & $\mathbf{7 0}$ & 75 \\
\hline questionnaires & $\mathbf{7 0}$ & $\mathbf{7 5}$ \\
\hline
\end{tabular}

The evaluation experience lasted on average $15 \mathrm{~min}$, from the moment of the meeting with the users until the closing of the questionnaire together with the UX operator.

In general, all users (145 in total) were positive towards the UXEs: some of them offered their contribution spontaneously by asking operators to join the virtual experience; others, after having been asked, decided to participate in a propositional manner; very few visitors refused to participate. While users' attitudes towards such kind of activities was differentiated according to age, cultural predisposition, background education, etc. almost all of them compiled the questionnaire-leaving no unanswered questions.

\subsection{Results of the UX Evaluations}

The user groups for the evaluation were mainly made of by women $(60 \%$ of Paestum users and $51 \%$ of Florence users). The medium age registered was around 34 years old, coming mainly from Italy. They came from schooling environments for what concerns Paestum $(76 \%)$ and from humanities (archaeology, teaching, architectures) for Florence (88\%); their technological vocation was addressed to smartphones (70\% out of the global users) and PCs (55\% out of the global users). Game console and HMD devices were not fully experienced yet, as for Paestum and Florence users.

General observations of users, in both locations, revealed a great sense of curiosity towards the VR application: people stayed in a row a long time before their turn to play with ArkaeVision Archeo, together with friends, parents and relatives. While waiting, they expressed their amazement, astonishment, but also their doubts about any possible issue they could encounter once worn the HMD over their heads. They made fun watching other people playing, trying to figure out what they were supposed to do; they also asked for more information about 3D modeling, the final place of installation, the price and other technical questions. They were particularly interested in the visual aspect of virtual 
reality; they were continuously asking "How did you do this?", "How is that so vivid in colors?", "How did you also include birds and flowers?". These questions simply arose from what they could see on the big monitor showing the experience of somebody else who was playing at that moment!

The general feeling of users were therefore motivating and intriguing. Both in Paestum and in Florence, a high percentage of users (respectively $89 \%$ and $76 \%$ ) autonomously approached the interactive area and stayed till the end of the experience.

By the way, observations made on users while playing with the ArkaeVision Archeo showed a great ability and predisposition of using the system alone, without any particular help or support by technician (at Paestum 14\% made it completely alone and 50\% with very small help while in Florence $23 \%$ made it alone and $42 \%$ with help). The remaining $36 \%$ in Paestum and $35 \%$ in Florence asked for help only at the very beginning of the experience or at the end (needed to wear the HMD and to take it off). Maybe in Florence the VR experience was a bit challenging, given the state of advancement of specific tasks of the application: here, observations revealed a high level of usability, but still hesitations of users in proceeding with the exploration completely alone. Such datum could not be evaluated, but still remarked by UX evaluator.

Users reported interaction as natural (Figure 16) (88\% in Paestum and $79 \%$ in Florence), quite intuitive to be used with the HMD and hand controllers (84\% in Paestum and 50\% in Florence) as well as practical in the handling and in the body movements ( $87 \%$ in Paestum and $81 \%$ in Florence). The small shift in results between the two locations about usability is surely referable to the average age of users: in Paestum, we had youngers-who are usually more accustomed to such interactive devices - while in Florence, we had quite more adults less addicted to VR and HMDs.

Users almost never felt tired, disturbed or annoyed during VR exploration of ArkaeVision Archeo ( $95 \%$ out of the global users). The small group of people who highlighted some issues referred to (a) the time spent standing still (usually aged users), (b) some locomotion effects like nausea or headache and (c) some external noises which disturbed the experience.

Shifting to a more cognitive sphere, users affirmed in the questionnaires to have felt a sense of profound immersion in the virtual Poseidonia and in the story (100\% out of the global users). The Figure 17 shows the seven most cited words in relation to sensations arisen during the VR experience. They were isolated and counted referring to open answers of users. In general, they refer to:

- $\quad$ time shifting and the chance to go back in time (24\% out of the global users);

- $\quad$ the high fidelity of forms and architectures (14\% out of the global users);

- the natural interaction and the immediateness of system's feedback ( $13 \%$ out of the global users);

- the general atmosphere recreated through colors, sounds and style of the virtual scenes $(15 \%$ out of the global users).

Open comments also empowered this sensation like "I was quite embarrassed to meet the Priestess; she seemed she was really looking at me", "The lights and the warmness of the lamps inside the ancient temple were vivid and realistic", "The bird watched me", "I felt a sense of wind in my hair".

Figure 18 shows the percentage of a closed question about users' preferences after their VR experience. Users were given five possible answers, with multiple-choice option. What was mostly liked by users were in line with other collected data:

- the global atmosphere made of colors, sounds and historical setting (22\% in Paestum and 28\% in Florence);

- the sense of immersion and the perceptive sensation of "being projected" into another world (25\% in Paestum and $20 \%$ in Florence);

- the vedutismo pictorial style and the "sense of ancient" in the graphic details (17\% in Paestum and $23 \%$ in Florence);

- more, the scenography, with its particular forms and characters (21\% in Paestum and $18 \%$ in Florence). 


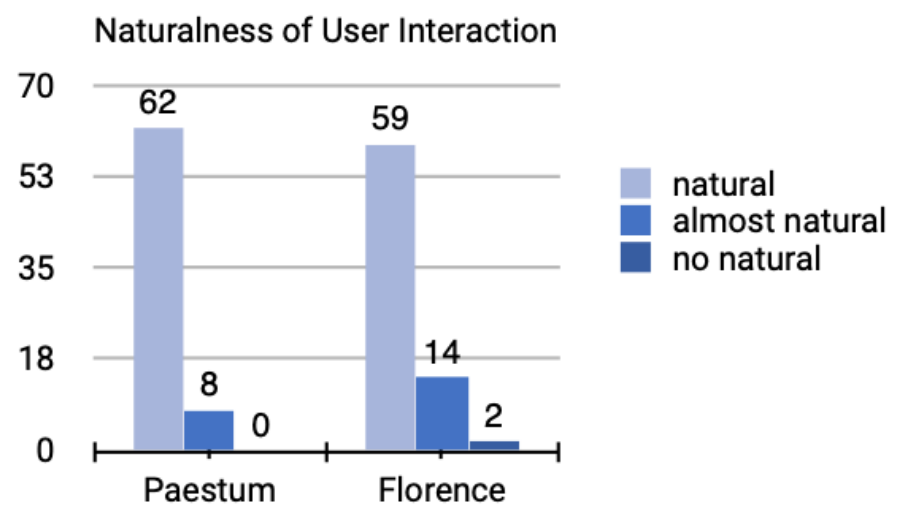

(a)

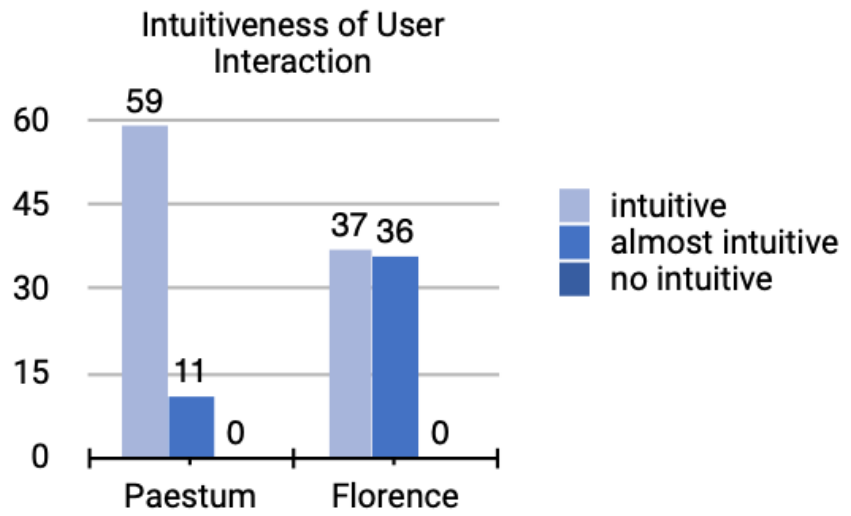

(b)

Feasibility of User Interaction

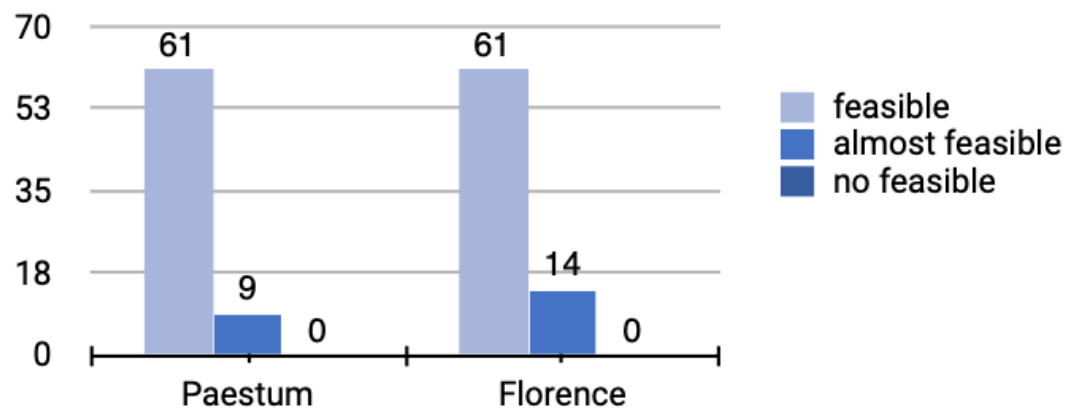

(c)

Figure 16. Preferences out of $70+75$ responses to the question "How did you find the interaction into the VR experience?". (a) Chart about the naturalness of the user-system interaction; (b) chart about the intuitiveness of the user-system interaction; (c) chart about the feasibility of the user-system interaction.

Users also pointed out some issues to be improved (Figure 19) such as the locomotion and the motion sickness; another point was the short version of the demo in Paestum, while, in Florence, they complained about the short time at their disposal to arrive at the end of the experience (given the long row to participate at the VR application). These aspects can be easily overcome when the ArkaeVision Archeo will meet its final destination and people can have enough time to play with it, with no distraction. Obviously, the two public occasions were not the exact context for the fruition of an immersive VR application rather than a presentation. About the sense of dizziness and nausea that someone felt, they are attributable to technical constraints which are still under development. Authors want to exploit these issues in the next releases of the VR application. 


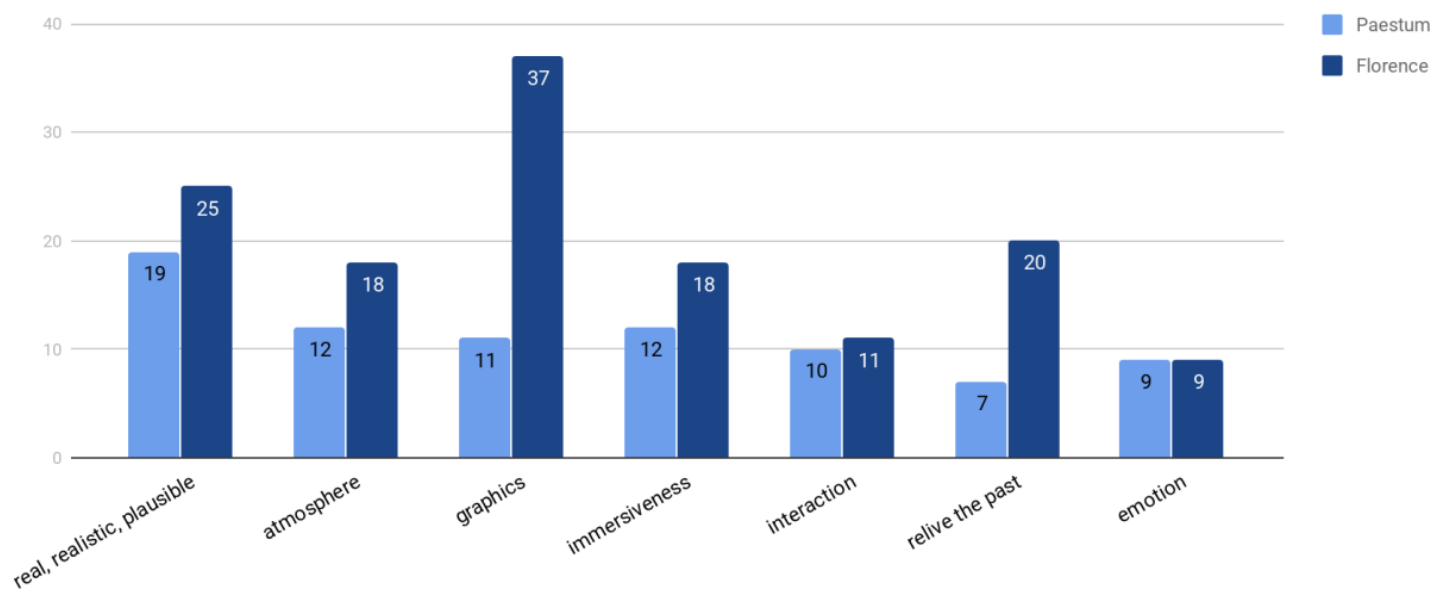

Figure 17. Preferences out of $70+75$ responses to the question "What did you feel immersed in exploration?".

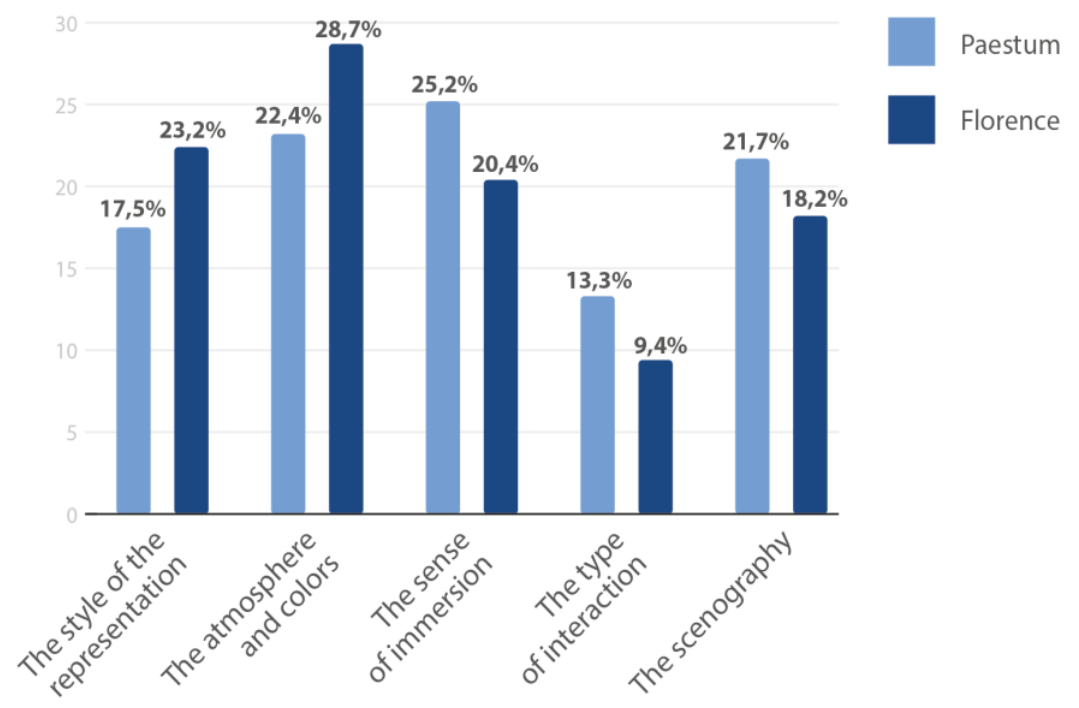

Figure 18. Preferences out of $70+75$ responses to the question "What did you prefer of the VR experience?".

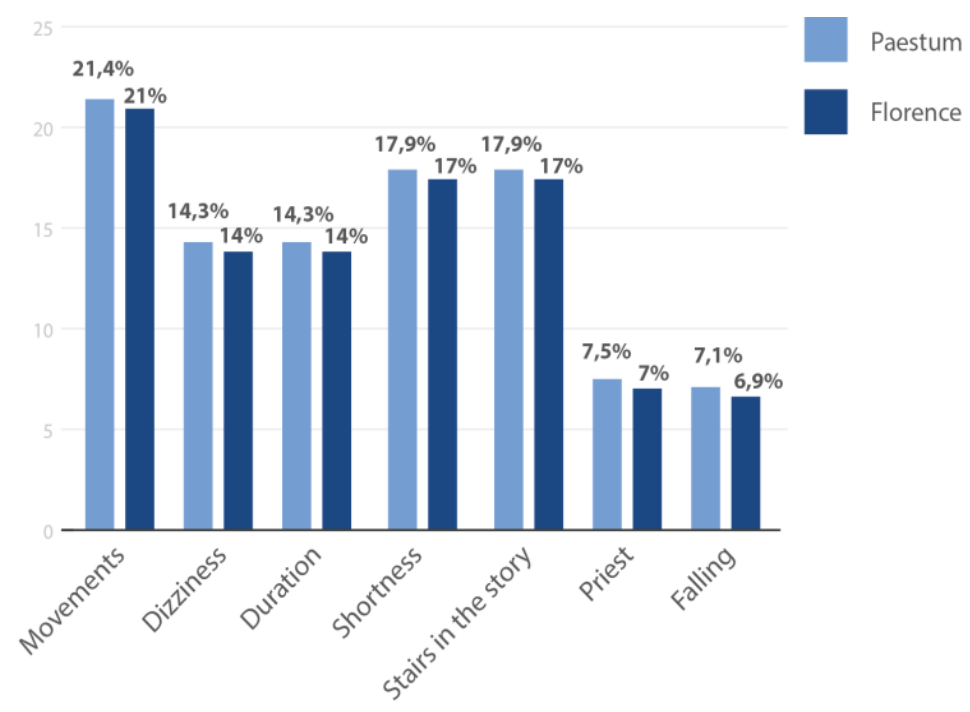

Figure 19. Preferences out of $70+75$ responses to the question "What did you dislike about this experience?". 
About storytelling, ArkaeVision Archeo proposed in Paestum was a demo, so it did not allow users to fully access complex content. No in-depth questions were made to test attention and memorization. Nonetheless, some information could be collected by users simply exploring the virtual environment, observing and understanding the reconstructed space: counting how many columns the temple had; which was the name of the goddess statue in the temple; recognizing the original colors of the facade of the temple and other visual elements which are part of the storytelling as well. In the open questions, there are indeed many comments relating to the architecture, the capitals, the environment of the naos with the statue of the goddess Hera, the gifts in the temple cell and the clothes of the priestess Ariadne. Some users expressed the desire to continue with the narration, because they are intrigued by Ariadne's words and movements; others are delighted to see the temple in 3D rebuilt, as it was presumably in its period of splendor and reduced to ruins today: the colors of the tympanum, the darkness of the interior caused by the torches, the brightness of the stones, the red and white color of the Ariadne's dress ... these are all silent, but evident narrative elements, which greatly help the users to "see", understand and remember the past. In Florence, instead, the storyline was solid and extremely informative thanks to dialogs, anecdotes, infographics and metadata spread all around VR exploration. In this way, it was possible to conduct a small evaluation on content, starting on the questions already done in Paestum. Results confirmed good level of memorability of the storytelling: almost $50 \%$ of users recognized and gave the exact naming to the statue placed in the naos of the temple (goddess Hera); $39 \%$ of users correctly remembered some details of the ritual happening in the VR application (on the altar outside of the temple); finally, to almost $70 \%$ of users it was clear the historical period they went back in time (fifth century BC). The remaining percentages related to unanswered questions.

Users initially had some expectations of what would await them during the virtual exploration of the temple of Hera II of Paestum. From the questionnaires emerged that most of them wanted "to be able to understand ancient architecture and see what a Greek temple was like", thus finalizing their interest in seeing ancient times. Experts in the field of $\mathrm{CH}$ wanted to "learn new things in an innovative and engaging way", as they understood the usefulness of new technologies and the potentiality of users' involvement; some people simply wanted to get excited, live the experience of "immersing themselves in the history" to experience "wonder" and "discover things". Most curious people and passionate about history, however, asked to "relive the civilization of the past" and "re-discover the ancient deeds of the city of Paestum", but also "meet historical characters".

Downstream of these requests and thoughts, a specific question was asked to users at the end of the experience, regarding the satisfaction; the average score assigned to the immersive experience was 9 in both locations.

\section{Discussion}

The disadvantages identified in the first evaluation (Paestum) can be found into [85]. They mainly related to (a) the motion sickness felt by users during VR exploration, (b) the poor naturalness of the digital guide of Ariadne and (c) some features of the storytelling (language, type of content ... ) not really addressing the target users. These enabled the revision of the system, especially for what concerned the usability and the sense of realism of the 3D environment and the character.

In general, as emerged from the data collected through the multi-partitioned analyses, ArkaeVision Archeo follows a (pro)active way of experiencing the DCH: the audio, composed of an evocative voice of Ariadne, supports the users along the virtual journey; moreover, a widespread soundscape frames the unfolding of the storyline, as lot of users confirmed; $3 \mathrm{D}$ visualization, highly photorealistic, with a romantic taste, acts as a backdrop for the events and it allows the recognition of objects, places and actions. The synergy between storytelling, emotional features (revealed into graphics and narrative nodes) and immersive exploration proved to be successful for this type of experience to a $\mathrm{CH}$ site as other works revealed too [14].

The interaction skills required during the virtual exploration allow users to learn while performing, according to the doctrine of learn-by-doing $[6,40,103]$. In ArkaeVision Archeo, the interaction takes 
place thanks to hand controllers, therefore the need to perform targeted and physical-tactile actions on a material device is fundamental. In case there are limitations in this sense, virtual experience would not be possible, if not guided by an external person.

All users are quite comfortable with the HMD and the hand controllers, considering such a way of behaving as natural and spontaneous. They can stand and move with a certain degree of freedom, always having the viewer on, connected with a wire to a computer; moreover, the same interaction cannot overcome certain spatial limits, given the need to be digitally traced in the real space. This configuration does not negatively influence users: they do not claim for chairs even if some of them reported motion sickness.

About users' emotional involvement, it is clear how ArkaeVision Archeo acts: colors, shapes, sounds and behaviors are useful to stimulate the "irrational" part of individuals and to generate motivation-that is the first aspect that pushes people to face technological solutions and lets the learning process to take place $[98,99]$. Such emotional components are exactly the ones that users affirmed to appreciate the most. Moreover, a correlation between the emotive state of users during VR exploration, their level of attention and their memorability was found: the more they are attentive to specific items or narrative nodes, the more they are emotionally involved in the action and tend to easily remember what just experienced.

Going back to Section 4.1 and the goals that authors wanted to survey out, in the following chapter we discuss more in depth some of the most relevant outcomes of the UXEs and, in general, move forward reflections and suggestions.

\subsection{Interactive Immersive Experience (Goal A)}

\subsubsection{Embodiment and Immersion in Virtual Poseidonia}

The HTC Vive viewer used for ArkaeVision Archeo exalts the natural capabilities of participants, reducing even more the distance between real and virtual. The immersive impression of "reality" reaches higher levels not only referring to what users see as meaningful and reliable, but also the way they can observe, explore, interact with is really coherent to their realistic behavioral attitudes.

HTC Vive excludes the vision of external reality; the latter is deleted from the users' visual and experiential field replacing the virtual one- the virtual Poseidonia. This progressive separation from real to virtual implies a great cognitive step for users, both in the perception of themselves and of the experience they are doing. This provide a deeper sense of immersion which pushes them to feel comfortable and willing to proceed with the experience.

This sensation, also called sense of "embodiment", determines therefore the level of users' involvement, the motivation to interact with the environment by measuring the users' actions and reactions to (virtual) events and tasks.

It is not a coincidence that nowadays VR technologies are progressing towards immersive devices which give users the impression of being totally immersed in the virtual context, making them loose the exact awareness of the real space in which they are located into [24,104].

\subsection{2. "Invisibility" of HMD Technology}

In general, the more the technology is well hidden, the more immersion in the virtual reality will be successful; the more invisible will be the technical expedients, the more the virtual environment will be realistic, stimulating in users a total sense of involvement, recognition and embodiment in it.

Let technology become invisible means working on usability and interface design in order to provide users with an experience as simple and intuitive as possible [4].

This will probably be the key concept in the development of next generation immersive VR like ArkaeVision Archeo: the level of involvement can vary according to how reliable are the features of what users are experiencing; however, the type of involvement must be stimulated by the environment rather than the technology behind it. 


\subsection{Emotional Experience (Goal B)}

Several surveys carried out in DCH field pointed out that the attention towards technology in museums is not long lasting $[4,5]$ and it shifts from a subject to another if content is not stimulating. For such a reason, working on cognitive and emotional paradigms may help.

Generally speaking, visual perception allows users to identify which characters are familiar to them in the forms, in the architectural lines of the monuments, in the colors of surfaces and in the material stratifications. The users read all these elements and try to compare them with their knowledge, recovering useful information from (visual) memory and creating logical-visual connections and associations, thus reconstructing new knowledge (and awareness). Thanks to the HTC Vive, the visual perception of ArkaeVision Archeo is amplified: the creation of mental models starting from the reading of the current one, is allowed by the technology itself, which makes visualizing the cultural good or site as they would appear in the past [9]. In addition, the visual memory is increased: the 3D features of the reconstructions, the fidelity of the photographic descriptions greatly facilitates the users in the process of imagining registration. Authors conclude that the capacity of users' visual memory may depend on:

A. Emotional content. The sight of a beautiful landscape, the presence of faces, a gradient of warm color, let strong emotions arise-as users affirmed during the UXEs - and they allow a profitable memorization-given the high percentage of correct answers about the historical content;

B. Presence of action. If there is an evolving action in the virtual image, then our brain almost unconsciously foreshadows the development of what will happen. This allows a greater emotional involvement of users in the scene they are watching at. Operators noticed an interesting relationship between the emotive state of users and their performances during the VR experience: the more users were positive and proactive towards specific tasks, the more they remembered visual details and "geo-referred" facts (units of information placed in specific points of the VR environment).

C. Observation perspective. The user's point of view with respect to visualization is relevant for emotional involvement and, therefore, guaranteeing a visual memory. The more the users' position is central to the virtual scene they are observing, the more their perception and sense of presence are vivid; in fact, by privileging a central point of view, like in ArkaeVision Archeo, users had the opportunity to grasp both the sense of the whole and the multiple details, thus having the chance to remember more effectively the "photography" of that specific experience-as the investigated users confirmed with their descriptions.

\subsection{Digital Characters \& Storytelling (Goal C)}

"Real" Characters and Sense of Dialog

ArkaeVision Archeo has a subjective navigation in the immersive VR exploration. This means that, on the one hand, (a) the quality of the storyline requires a plot that constitutes a challenging roadmap for the users, but, on the other, (b) it suggests a simple and linear narrative scheme.

The first assumption recalls the need to optimize the memory-machine power: a complex interaction model between the users and the digital characters with high responsive potential, involves memory-machine resources such as to make the interaction reasonable with one character at a time. In fact, due to the highly realistic effects of characters' behavior and appearance, even assuming different "agents" in the story, it is appropriate to limit their interaction with the users to one at a time. In ArkaeVision Archeo we have indeed the only active character of Ariadne.

The second assumption relates to the cognitive sphere. In a highly immersive VR context, which gives a deeply realistic interaction with the virtual entity, it is necessary to take into account the adaptive needs of users to a new experience, which require an effort of cognitive resources; it is therefore preferable to simplify interactions with agents and the general narrative scheme. 
For the above-mentioned considerations, the ArkaeVision Archeo was based on a subjective exploration of the space, rebuilt in a specific historical period. After a video premise and the subsequent real interactive scenario, users enter in relation with the main character: the priestess. She has recognizable female physical characteristics; she moves inside the temple and she relates to the users as a guide.

\section{Conclusions \& Future Perspectives}

Technological fruition nowadays assumes a complementary role to the direct experience of $\mathrm{CH}$ and cannot replace it. However, it cannot be forgotten that the indirect experience of the cultural goods, in many cases, is the only solution due to restoration issues, lack of exhibition space, uniqueness of the cultural good or site, unavailability for fruition due to loan, distance from the context of discovery, closure of the museum structure, etc.

The technologically mediated usage, therefore, provides the empowerment of the ways of experiencing cultural objects, places and characters, through the creation of virtual animated scenarios of the past.

The ArkaeVision project, especially ArkaeVision Archeo, follows this streamline trying to push at the maximum the concept of experiential cultural experience and emotional involvement through digital immersive devices.

In the next future, ArkaeVision Archeo will find a permanent position in a national museum, as well as other components of the project like ArkaeVision Art and the web portal, fully functioning very soon.

Author Contributions: A.P. (Alfonsina Pagano) is a research fellow at CNR ISPC of Rome; for the project, she gave her contribution in methodology, formal analysis, UX investigation. She contributed to the conceptualization, screenwriting, writing - review and editing of this study. I.C. is an archaeologist and Accounting Senior of ArkaeVision project at Digitalcomoedia; for the project, she gave her contribution in validation of archaeological resources. She contributed to the writing of this study. A.P. (Augusto Palombini) is a researcher at CNR ISPC of Rome; he was PI and partner of the ArkaeVision project, working on the general setting of the historical reconstructions and on screenwriting, supervised the documentation work. He contributed to the writing of this study. M.D.N. is a physicist with a specialization in artificial intelligence and data acquisition systems. He is adjunct professor in Computer Graphics and Virtual Reality at University Parthenope of Naples and is the CTO of Digitalcomoedia. He has coordinated the technical activities done for the ArkaeVision project. He contributed to the writing of this paper. S.R. is a researcher at University of Molise focused on virtual and augmented/mixed reality, haptics systems and human-computer interaction. He is member of IEEE and GIRPR/IAPR and serves as external expert for the Research Executive Agency of the European Commission. He has been a supervisor for the IT research components of the Arkaevision project. He contributed to the writing of this paper. G.B. is founder and CEO of Digitalcomedia. He is Experience design, CGI and 3D video production Supervisor and Virtual Reality, Augmented Reality, Computer animation, communication and Digital Contect Production Executive. He's the Executive Producer, Experiential Director and he followed funding acquisitions of the ArkaeVision project. He contributed to the supervision of this paper. All authors have read and agree to the published version of the manuscript.

Funding: ArkaeVision is a research and development project, financed by the MISE-Fund for Sustainable Growth-Call for proposals "HORIZON 2020" PON I \& C 2014-2020.

Acknowledgments: Authors acknowledge colleagues who contributed to the realization of the ArkaeVision project, as well as the Archaeological Museum of Paestum, his director Doc. Gabriel Zuchtriegel and the museum staff.

Conflicts of Interest: The authors declare no conflict of interest.

\section{References}

1. Bekele, M.; Champion, E. A Comparison of Immersive Realities and Interaction Methods: Cultural Learning in Virtual Heritage. Front. Robot. AI 2019, 6. [CrossRef]

2. Drossis, G.; Birliraki, C.; Stephanidis, C. Interaction with Immersive Cultural Heritage Environments Using Virtual Reality Technologies. In Communications in Computer and Information Science; Springer: Berlin/Heidelberg, Germany, 2018; pp. 177-183. [CrossRef] 
3. Galdieri, R.; Carrozzino, M. Natural Interaction in Virtual Reality for Cultural Heritage. In VR Technologies in Cultural Heritage. VRTCH 2018; Communications in Computer and Information Science; Duguleană, M., Carrozzino, M., Gams, M., Tanea, I., Eds.; Springer: Berlin/Heidelberg, Germany, 2019; Volume 904.

4. Pietroni, E.; Pagano, A.; Fanini, B. UX Designer and Software Developer at the mirror: Assessing sensory immersion and emotional involvement in Virtual Museums. In Special Issue of "Studies in Digital Heritage" on "Perceiving Cultural Heritage through Digital Technologies"; Indiana University: Bloomington, Indiana, 28 February 2018; pp. 13-41.

5. Pietroni, E.; Ferdani, D.; Forlani, M.; Pagano, A.; Rufa, C. Bringing the Illusion of Reality Inside Museums-A Methodological Proposal for an Advanced Museology Using Holographic Showcases. J. Inform. 2019, 6. [CrossRef]

6. Kolb, D. Experiential Learning: Experience as the Source of Learning and Development; Prentice Hall: Englewood Cliffs, NJ, USA, 1984.

7. Bloom, B.B.; Krathwohl, D.R.; Masia, B.B. Handbook II. Affective Domain; David McKay Company: New York, NY, USA, 1957.

8. Bloom, B.S. Reflections on the development and use of the taxonomy. In Bloom's Taxonomy: A Forty-year Retrospective, Yearbook of the National Society for the Study of Education; Anderson, L.W., Sosniak, L.A., Eds.; National Society for the Study of Education: Chicago, IL, USA, 1994; Volume 93, ISSN 1744-7984.

9. Bloom, B.S.; Engelhart, M.D.; Furst, E.J.; Hill, W.H.; Krathwohl, D.R. Taxonomy of educational objectives: The classification of educational goals. In Handbook I: Cognitive Domain; David McKay Company: New York, NY, USA, 1956.

10. Raptis, G.E.; Fidas, C.; Avouris, N. Do Game Designers' Decisions Related to Visual Activities Affect Knowledge Acquisition in Cultural Heritage Games? An Evaluation From a Human Cognitive Processing Perspective. J. Comput. Cult. Herit. 2019, 12, 1-25. [CrossRef]

11. Sternberg, R.J.; Sternberg, K. Cognitive Psychology; Wadsworth Cengage Learning: Belmont, CA, USA, 2009.

12. Antinucci, F. Comunicare nel Museo; Laterza: Bari, Italy, 2014.

13. Antinucci, F. Parola e Immagine; Storia di due Tecnologie; Laterza: Bari, Italy, 2011.

14. Konstantakis, M.; Caridakis, G. Adding Culture to UX: UX Research Methodologies and Applications. J. Comput. Cult. Herit. 2020, 13, 1-17. [CrossRef]

15. Gockel, B.; Graf, H.; Pagano, A.; Pescarin, S.; Eriksson, J. VMUXE. An Approach to User Experience Evaluation for Virtual Museums. In Design, User Experience, and Usability. Design Philosophy, Methods, and Tools; DUXU 2013. Lecture Notes in Computer Science; Marcus, A., Ed.; Springer: Berlin/Heidelberg, Germany, 2013; Volume 8012, pp. 262-272.

16. Ashworth, M.; Argote, L.; Mukhopadhyay, T. The Effect of Information Technology on Knowledge Acquisition, Retention, and Transfer. In Proceedings of the 25th Annual International Conference on Information Systems (ICIS), Milwaukee, WI, USA, 10-13 December 2006; pp. 11-21.

17. Markovic, G.; Vukovac, M.P.; Klicek, B. A Study on Knowledge Gain and Retention when Using Multimedia Learning Materials of Different Quality. J. Inf. Organ. Sci. 2015, 39, 33-48.

18. Elhachemi, T.; Saoula, O.; Elkheloufi, A.; Benabid, E. Towards A Better Understanding of the Antecedents of Knowledge Acquisition and Its Outcome: A Two- Fold Proposed Framework. Test Eng. Manag. 2020, 82, 1957-1971.

19. Roberts, J. Chapter 4: Knowledge Acquisition, Retention, and Transfer. In A Very Short, Fairly Interesting and Reasonably Cheap Book about Knowledge Management; Sage: Thousand Oaks, CA, USA, 2008. [CrossRef]

20. Pagano, A.; Pietroni, E.; Poli, C. An integrated methodological approach to evaluate virtual museums in real museum contexts. In Proceedings of the 9th Annual International Conference of Education, Research and Innovation (ICERI), Seville, Spain, 14-16 November 2016; ISBN 978-84-617-5895-1.

21. Pietroni, E.; Pagano, A.; Amadei, M.; Galiffa, F. Livia's Villa Reloaded Virtual Museum: User Experience Evaluation. In Proceedings of the 9th annual International Conference of Education, Research and Innovation (ICERI), Seville, Spain, 14-16 November 2016; ISBN 978-84-617-5895-1.

22. Cipresso, P.; Giglioli, I.A.C.; Raya, M.A.; Riva, G. The Past, Present, and Future of Virtual and Augmented Reality Research: A Network and Cluster Analysis of the Literature. Front. Psychol. 2018, 9, 2086, PMID: 30459681, PMCID: PMC6232426. [CrossRef] [PubMed]

23. Au, E.H.; Lee, J.J. Virtual reality in education: A tool for learning in the experience age. Int. J. Innov. Educ. 2017, 4, 215. [CrossRef] 
24. Rizvic, S.; Boskovic, D.; Okanovic, V.; Sljivo, S.; Zukic, M. Digital Storytelling. In Visual Computing for Cultural Heritage; Liarokapis, F., Voulodimos, A., Doulamis, N., Doulamis, A., Eds.; Springer: Berlin/Heidelberg, Germany, 2020; pp. 347-367. [CrossRef]

25. Sylaiou, S.; Dafiotis, P. Storytelling in Virtual Museums: Engaging A Multitude of Voices. In Visual Computing for Cultural Heritage; Liarokapis, F., Voulodimos, A., Doulamis, N., Doulamis, A., Eds.; Springer: Berlin/Heidelberg, Germany, 2020; pp. 369-388. [CrossRef]

26. Mackay, D.G.; Shafto, M.; Taylor, J.K.; Marian, D.E.; Abrams, L.; Dyer, J.R. Relations between emotion, memory, and attention: Evidence from taboo Stroop, lexical decision, and immediate memory tasks. Mem. Cogn. 2004, 32, 474-488. [CrossRef]

27. Flaisch, T.; Steinhauser, M.; Schupp, H.T. Adaptive cognitive control attenuates the late positive potential to emotional distractors. NeuroImage 2019, 200, 51-58. [CrossRef]

28. Schubring, D.; Schupp, H. Emotion and attention effects as revealed by brain oscillations. In S. Schindler (Chair), Electrocortical Responses in Emotion Processing: Insights From Healthy Participants, Amygdala-Resection and Psychopathological Patients. Symposium Conducted at the Meeting of the Society of Psychophysiological Research; Society for Psychophysiological Research: Washington, DC, USA, 2019.

29. Schupp, H.T.; Stockburger, J.; Codispoti, M.; Junghöfer, M.; Weike, A.I.; Hamm, A.O. Selective Visual Attention to Emotion. J. Neurosci. 2007, 27, 1082-1089. [CrossRef] [PubMed]

30. Smith, S.D.; Most, S.B.; Newsome, L.A.; Zald, D.H. An emotion-induced attentional blink elicited by aversively conditioned stimuli. Emotion 2006, 6, 523-527. [CrossRef] [PubMed]

31. Walker, W.R.; Skowronski, J.J.; Gibbons, J.A.; Vogl, R.J.; Ritchie, T. Why people rehearse their memories: Frequency of use and relations to the intensity of emotions associated with autobiographical memories. Memory 2009, 17, 760-773. [CrossRef] [PubMed]

32. Skowronski, J.J.; Walker, W.R.; Henderson, D.X.; Bond, G.D. Chapter Three-The Fading Affect Bias: Its History, Its Implications, and Its Future. In Advances in Experimental Social Psychology; Academic Press: Cambridge, MA, USA, 2014; Volume 49, pp. 163-218. [CrossRef]

33. Lenzi, L. Neurofisiologia e Teorie Della Mente; Vita e Pensiero: Milan, Italy, 2005.

34. Zan, R. Il ruolo cruciale del pensiero narrativo nella comprensione dei problemi. Didattica Della Mat. Dalla Ric. Alle Prat. D'aula 2017, 46-57. [CrossRef]

35. Dugan, J.E. Audio-Visual Methods in Teaching; The Dryden Press: New York, NY, USA, 1955. [CrossRef]

36. Jackson, J. Myths of Active Learning: Edgar Dale and the Cone of Experience. J. Hum. Anat. Physiol. Soc. 2016, 20, 51-53. [CrossRef]

37. McClusky, H.Y. The Content of Motion Pictures. Edgar DaleChildren's Attendance at Motion Pictures. Edgar Dale. Elem. Sch. J. 1936, 36, 552-553. [CrossRef]

38. Subramony, D.; Molenda, M.; Betrus, A.; Thalheimer, W. The Mythical Retention Chart and the Corruption of Dale's Cone of Experience. Educ. Technol. 2014, 54, 6-16.

39. Fòrema. Experiential Learning. Metodi, Tecniche E Strumenti per IL Debriefing: Metodi, Tecniche E Strumenti per IL Debriefing; FrancoAngeli: Milan, Italy, 2015.

40. Moon, J.A. A Handbook of Reflective and Experiential Learning: Theory and Practice; Routledge: New York, NY, USA, 2004.

41. Piaget, J. Avviamento al Calcolo; La Nuova Italia: Firenze, Italy, 1956.

42. McQueen, B.; Nowak, A.; Kjaer Olsen, J. Learning by Doing in 3D Environments: Collaborative Efforts in Second Life and OpenSim. In Handbook of Research on Collaborative Teaching Practice in Virtual Learning Environments; IGI Global: Hershey, PA, USA, 2017.

43. Alais, D.; Newell, F.; Mamassian, P. Multisensory Processing in Review: From Physiology to Behaviour. Seeing Perceiving 2010, 23, 3-38. [CrossRef]

44. Ferré Veciana, J.; Aribau Montón, E. El Desarrollo Neurofuncional Del NIño y Sus Trastornos. Visión, Aprendizaje y Otras Funciones Cognitivas; Ediciones Lebón: Barcelona, Spain, 2008.

45. Hellier, J.L. Congenital insensitivity to pain. In The Five Senses and Beyond: The Encyclopedia of Perception; Hellier, J.L., Ed.; Greenwood: Santa Barbara, CA, USA, 2016; pp. 118-119.

46. Hutmacher, F. Why Is There So Much More Research on Vision Than on Any Other Sensory Modality? Front. Psychol. 2019, 10, 2246. [CrossRef] 
47. Katifori, A.; Tsitou, F.; Pichou, M.; Kourtis, V.; Papoulias, E.; Ioannidis, Y.; Roussou, M. Exploring the Potential of Visually-Rich Animated Digital Storytelling for Cultural Heritage. In Visual Computing for Cultural Heritage; Liarokapis, F., Voulodimos, A., Doulamis, N., Doulamis, A., Eds.; Springer: Berlin/Heidelberg, Germany, 2020; pp. 325-345. [CrossRef]

48. Stokes, D.; Biggs, S. The dominance of the visual. In Perception and its Modalities; Stokes, D., Matthen, M., Biggs, S., Eds.; Oxford University Press: Oxford, UK, 2014; pp. 350-378.

49. Foni, A.E.; Papagiannakis, G.; Magnenat-Thalmann, N. A taxonomy of visualization strategies for cultural heritage applications. J. Comput. Cult. Herit. 2010, 3, 1-21. [CrossRef]

50. Alexander, A.L.; Brunyé, T.; Sidman, J.; Weil, S.A. From Gaming to Training: A Review of Studies on Fidelity, Immersion, Presence, and Buy-in and Their Effects on Transfer in PC-Based Simulations and Games; Aptima, Inc.: Woburn, MA, USA, 2005.

51. Ibrahimi, D. La Visione in Relazione ai Problemi di Apprendimento nella Lettura. In NEUROSCIENZE, Rivista Online. 27 April 2012. Available online: https:/www.neuroscienze.net/wp-content/uploads/2012/04/ La-Visione-in-Relazione-ai-Problemi-di-Apprendimento-nella-Lettura.pdf (accessed on 23 December 2019).

52. Davis, K.; Christodoulou, J.; Seider, S.; Gardner, H. The Theory of Multiple Intelligences. In The Cambridge Handbook of Intelligence; Sternberg, R.J., Kaufman, B., Eds.; Cambridge University Press: Cambridge, UK, 2011; pp. 485-503. ISBN 978-0521518062.

53. Gardner, H. Multiple Intelligences: New Horizons in Theory and Practice; Basic Books: New York, NY, USA, 2006; ISBN 978-0465047680.

54. Roussou, M. Immersive Interactive Virtual Reality in the Museum. In Proceedings of the TiLe, Foundation of The Hellenic World, Product, Greece, 6-9 June 2002; p. 2.

55. Öhman AMineka, S. Fears, Phobias, and Preparedness: Toward and Evolved Module of Fear and Fear Learning. Psychol. Rev. 2001, 108, 483-522. [CrossRef] [PubMed]

56. Shafer, D.; Carbonara, C.P.; Korpi, M.F. Factors Affecting Enjoyment of Virtual Reality Games: A Comparison Involving Consumer-Grade Virtual Reality Technology. Games Health J. 2019, 8, 15-23. [CrossRef] [PubMed]

57. Boletsis, C. The New Era of Virtual Reality Locomotion: A Systematic Literature Review of Techniques and a Proposed Typology. Multimodal Technol. Interact. 2017, 1, 24. [CrossRef]

58. Bozgeyikli, E.; Raij, A.; Katkoori, S.; Dubey, R. Point \& teleport locomotion technique for virtual reality. In Proceedings of the 2016 Annual Symposium on Computer-Human Interaction in Play, Austin, TX, USA, 15 October 2016; pp. 205-216.

59. Mortara, M.; Catalano, C.E.; Bellotti, F.; Fiucci, G.; Houry-Panchetti, M.; Petridis, P. Learning cultural heritage by serious games. J. Cult. Herit. 2014, 15, 318-325. [CrossRef]

60. Truby, J. Anatomy of a Story; Faber and Faber: London, UK, 2007.

61. Mortara, M.; Catalano, C. 3D Virtual environments as effective learning contexts for cultural heritage. Ital. J. Educ. Technol. 2018, 26, 5-21.

62. Doukianou, S.; Daylamani-Zad, D.; Paraskevopoulos, I. Beyond Virtual Museums: Adopting Serious Games and Extended Reality (XR) for User-Centred Cultural Experiences. In Visual Computing for Cultural Heritage; Liarokapis, F., Voulodimos, A., Doulamis, N., Doulamis, A., Eds.; Springer: Berlin/Heidelberg, Germany, 2020; pp. 283-299. [CrossRef]

63. Fassone, R. Cinema e Videogiochi; Carocci: Rome, Italy, 2017.

64. Anderson, E.F.; McLoughlin, L.; Liarokapis, F.; Peters, C.; Petridis, P.; De Freitas, S. Developing serious games for cultural heritage: A state-of-the-art review. Virtual Real. 2010, 14, 255-275. [CrossRef]

65. Dickey, M.D. Game Design Narrative for Learning: Appropriating Adventure Game Design Narrative Devices and Techniques for the Design of Interactive Learning Environments. Educ. Technol. Res. Dev. 2006, 54, 245-263. [CrossRef]

66. Palombini, A. Storytelling and telling history. Towards a grammar of narratives for Cultural Heritage dissemination in the Digital Era. J. Cult. Herit. 2017, 24, 134-139. [CrossRef]

67. Greco, E. Paestum. La Città Dei Tre Templi; Vision: Roma, Italy, 2019.

68. Torelli, M. Paestum Romana. Ingegneria per la Cultura; Marsilio Editore: Roma, Italy, 1999.

69. Zuchtriegel, G. Colonization and Subalternity in Classical Greece: Experience of the Non-Elite Population; Cambridge University Press: Cambridge, UK, 2017.

70. Zuchtriegel, G. Piranesi a Paestum. Il Suono dell'architettura; Artém: Napoli, Italy, 2017. 
71. Mertens, D. I templi di Paestum paradigmi per lo studio dell'architettura classica. In Architettura Pubblica E Privata Nell'Italia Antica; Quilici, L., Quilici Gigli, S., Eds.; Gangemi: Roma, Italy, 2007; pp. 143-161.

72. Biraschi, A.M. Strabone, Geografia: L'Italia, Book V, VI; BUR Rizzoli: Milano, Italy, 1988; ISBN 88-17-16687-1.

73. Greco, E.; Greco, G.; Pontrandolfo, A. Da Poseidonia a Paestum; (Paestum. La Città e il Museo 2); Ingegneria Della Cultura: Roma, Italy, 2002.

74. De La Genière, J.; Greco, G. (Eds.) Il Santuario di Hera alla Foce del Sele. Indagini e studi 1987-2006; Società Magna Grecia: Roma, Italy, 2010; Volume 1.

75. Zuchtriegel, G. Il tempio di Nettuno tra emblema e caso di studio. In "L'EMBLEMA DELL'ETERNITÀ". Il tempio di Nettuno a Paestum tra Archeologia, Architettura e Restauro; Mangone, F., Russo, V., Zuchtriegel, G., Eds.; ETS: Pisa, Italy, 2019; pp. 13-26.

76. Zuchtriegel, G. Da Poseidonia a Paestum: Archeologia di un nome. In Dialogando. Studi in Onore di Mario Torelli; Masseria, C., Marroni, E., Eds.; ETS: Pisa, Italy, 2017; pp. 469-477.

77. Rescigno, C. Tra il tempio di Nettuno e la Basilica: Osservazioni sul corpus delle terrecotte architettoniche pestane. In "L'EMBLEMA DELL'ETERNITÀ". Il tempio di Nettuno a Paestum tra Archeologia, Architettura e Restauro; Mangone, F., Russo, V., Zuchtriegel, G., Eds.; ETS: Pisa, Italy, 2019; pp. 59-72.

78. Mertens, D. Il tempio di Nettuno alla luce di un nuovo rilievo. In "L'EMBLEMA DELL'ETERNITÀ". Il Tempio dI Nettuno a Paestum Tra Archeologia, Architettura e Restauro; Mangone, F., Russo, V., Zuchtriegel, G., Eds.; ETS: Pisa, Italy, 2019; pp. 27-58.

79. Cipriani, M. Il ruolo di Hera nel santuario meridionale di Poseidonia. In Héra. Images, Espaces, Cultes. Actes du Colloque International de Lille; OpenEdition: Napoli, Italy, 1993; Volume 15, pp. 211-225. ISBN 9782918887201. [CrossRef]

80. Hellström, P.; Alroth, B. Religion and Power in the Ancient Greek World. In Proceedings of the Uppsala Symposium 1993; Acta Universitatis Upsaliensis: Stockholm, Sweden, 1996.

81. Strøm, I. Evidence from the Sanctuaries. In Greece between East and West 10th-8th centuries BC: Papers of the meeting at the Institute of Fine Arts, New York University, March 15th-16th, 1990; Kopcke, G., Tokumaru, I., Eds.; Verlag Philipp von Zabern: Mainz, Germany, 1992; pp. 46-60.

82. Torelli, M. Il rango, il Rito e L'immagine; Mondadori Electa: Milano, Italy, 1997.

83. Scarpi, P. La religione greca. In Storia Delle Religioni. Mondo Classico. Europa Pre-Cristiana; Filoramo, G., Ed.; Laterza: Bari, Italy, 2005; pp. 41-151.

84. Mylonopoulos, J. Greek Sanctuaries as Places of Communication through Rituals: An Archaeological Perspective. In Ritual and Communication in the Graeco-Roman World; OpenEdition: Napoli, Italy, 2006; pp. 69-110.

85. Bozzelli, G.; Raia, A.; Ricciardi, S.; De Nino, M.; Barile, N.; Perrella, M.; Tramontano, M.; Pagano, A.; Palombini, A. An integrated VR/AR framework for user-centric interactive experience of cultural heritage: The ArkaeVision project. Digit. Appl. Archaeol. Cult. Herit. 2019, 15, e00124. [CrossRef]

86. Arnab, S.; Lim, T.; Carvalho, M.B.; Bellotti, F.; de Freitas, S.; Louchart, S.; Suttie, S.; Berta, R.; De Gloria, A. Mapping Learning and Game Mechanics for Serious Games Analysis; Wiley: Hoboken, NJ, USA, 2015.

87. Deterding, S.; Dixon, D.; Khaled, R.; Nacke, L. From Game Design Elements to Gamefulness: Defining "Gamification". In Proceedings of the 15th International Academic MindTrek Conference: Envisioning Future Media Environments, Tampere, Finland, 6-8 October 2011; pp. 9-15. [CrossRef]

88. Carvalho, M. Serious Games for Learning: A Model and a Reference Architecture for Efficient Game Development; Tilburg University: Tilburg, The Netherlands, 2017.

89. Csikszentmihalyi, M. Flow. The Psychology of Optimal Experience; Alpina: Buchloe, Germany, 2011.

90. Wilhelmsson, U.; Backlund, P. Everyone Is not a Gamer! Developing Cultural Heritage Experiences for Diverse Audiences. In Visual Computing for Cultural Heritage; Liarokapis, F., Voulodimos, A., Doulamis, N., Doulamis, A., Eds.; Springer: Berlin/Heidelberg, Germany, 2020; pp. 263-281. [CrossRef]

91. Majewski, J. Cultural heritage in role-playing video games: A map of approaches. Furnace 2015, 2, 24-36.

92. Craig, A.B.; Sherman, W.R.; Will, J.D. Developing Virtual Reality Applications: Foundations of Effective Design; Morgan Kaufmann: Burlington, MA, USA, 2009.

93. Day, A.M.; Arnold, D.; Havemann, S.; Fellner, D. Combining polygonal and subdivision surface approaches to modelling and rendering of urban environments. Comput. Graph. 2004, 28, 497-507. [CrossRef] 
94. Achenbach, J.; Waltemate, T.; Latoschik, M.E.; Botsch, M. Fast generation of realistic virtual humans. In Proceedings of the 23rd ACM Symposium on Virtual Reality Software and Technology, Gothenburg, Sweden, 8-10 November 2017; pp. 1-10.

95. Airasian, P.W.; Cruikshank, K.A.; Mayer, R.E.; Pintrich, P.R.; Raths, J.; Wittrock, M.C. A Taxonomy for Learning, Teaching and Assessing: A Revision of Bloom's Taxonomy of Educational Objectives; Anderson, L.W., Krathwohl, D.R., Eds.; Allyn and Bacon: Boston, MA, USA, 2000; ISBN 978-0-8013-1903-7.

96. Agazzi, E.; Fortunati, V. Memoria e Saperi; Meltemi Editore Srl: Rome, Italy, 2007.

97. Dave, R.; Harrow, A.J. Handbook III. Psychomotor Domain; David McKay Company: New York, NY, USA, 1976.

98. Goleman, D. Emotional Intelligence: Why It Can Matter More Than IQ; Bloomsbury: London, UK, 1995.

99. Goleman, D. Intelligenza Emotiva. Che Cos'è e Perché Può Renderci Felici; Bur: Milano, Italy, 2011.

100. Pagano, A.; Armone, G.; De Sanctis, E. Virtual Museums and Audience Studies. The case of Keys To Rome exhibition. In Proceedings of the "Digital Heritage 2015". International Congress, Granada, Spain, 28 September-2 October 2015.

101. Kuniavsky, M. Observing The User Experience-A Practitioner's Guide to User Research; Morgan Kaufmann Publishers: Burlington, MA, USA, 2003.

102. Garrett, J. Elements of User Experience: User-Centered Design for the Web; New Riders Press: Indianapolis, IN, USA, 2002.

103. Piaget, J. Development and learning. In Piaget Rediscovered: A Report on the Conference of Cognitive Studies and Curriculum Development; Ripple, R.E., Rockcastle, V.N., Eds.; Cornell University: Ithaca, NY, USA, 1964; pp. 7-20.

104. Palombini, A. Narrazione e virtualità: Possibili prospettive per la comunicazione museale. Digit. WEB 2012, 1, 9-22, ISSN: 1972-6201.

(C) 2020 by the authors. Licensee MDPI, Basel, Switzerland. This article is an open access article distributed under the terms and conditions of the Creative Commons Attribution (CC BY) license (http://creativecommons.org/licenses/by/4.0/). 